No. $2006 / 12$

Why Do Contracts Differ between VC Types? Market Segmentation versus Corporate Governance Varieties

Julia Hirsch and Uwe Walz 


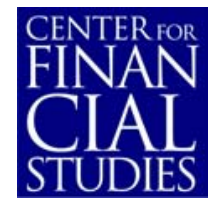

\section{Center for Financial Studies}

The Center for Financial Studies is a nonprofit research organization, supported by an association of more than 120 banks, insurance companies, industrial corporations and public institutions. Established in 1968 and closely affiliated with the University of Frankfurt, it provides a strong link between the financial community and academia.

The CFS Working Paper Series presents the result of scientific research on selected topics in the field of money, banking and finance. The authors were either participants in the Center's Research Fellow Program or members of one of the Center's Research Projects.

If you would like to know more about the Center for Financial Studies, please let us know of your interest.

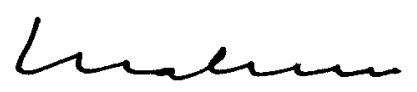

Prof. Dr. Jan Pieter Krahnen

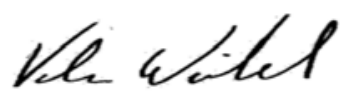

Prof. Volker Wieland, Ph.D. 


\title{
Why Do Contracts Differ between VC Types? Market Segmentation versus Corporate Governance Varieties*
}

\author{
Julia Hirsch ${ }^{1}$ and Uwe Walz ${ }^{2}$
}

\section{March 2006}

\begin{abstract}
:
The main objective of the present paper is to disentangle observed differences in the design of contracts across VC types into firm selection effects and corporate governance differences between VC types (different contracts). Based on a theoretical approach developed in the first part of the paper, we investigate in the second part these issues empirically by using a unique, hand-collected German data set consisting of all contractual details of VC investments into 290 entrepreneurial firms in the period 1990-2004. By employing various matching procedures, we show that VC types differ in both firm choice and corporate governance approach.
\end{abstract}

JEL Classification: G24, G32, G34

Keywords: Venture Capital, Corporate Governance, Matching, Contract Design

\footnotetext{
* This paper is part of a larger research cooperation between the Center for Financial Studies and KfW. We would like to thank Carsten Bienz and Volker Zimmermann for valuable comments, all KfW employees at KI for their support and especially Andreas Weber (KfW) for his help. All errors remain ours. We gratefully acknowledge financial support by German Research Foundation (DFG).

1 Goethe University Frankfurt, Schumannstraße 60, 60325 Frankfurt am Main, Germany. Tel : +49 (0) 6979822702. Email: jhirsch@wiwi.uni-frankfurt.de

2 Goethe University Frankfurt, Schumannstraße 60, 60325 Frankfurt am Main, Germany. Tel : +49 (0) 6979822775.

Email: uwe.walz@wiwi.uni-frankfurt.de
} 


\section{Introduction}

In recent years, the relationship between venture capitalists (VCs) and their portfolio firms has attracted significantly increasing attention in the popular press but also in academic research. One of the major questions in that respect is whether there exists, after controlling for firm characteristics, an optimal corporate governance design between the portfolio firm and its investor (the VC) or, whether we observe significant differences most notably across countries but as well across VC firms and types which prevail over time. By focusing on the contractual design between VCs and portfolio firms, we address the latter issue in detail and the former issue indirectly.

We concentrate on two main, specific questions. First, do different types of VCs (i.e. bank-dependent, public or independent VCs) negotiate different types of contracts when financing the same type of firms or are observed differences in contractual design across different VCs only due to the fact that different VCs select different firms? That is, we want to disentangle observed differences in the design of contracts between VCs and their portfolio firms into firm selection effects and actual differences in the corporate governance approaches between VC types. Second, depending on the answer of the first question we ask how precisely the differences across VC types (of either contractual design and/or selected firms) look like.

In a first step, we address these questions by building up a stylized theoretical model which allows for separation and pooling of firms financed by different VCs. This modelling approach enables us to derive testable hypotheses concerning the equilibrium behavior of VC firms. In a second step, we use a hand-collected German data set to respond to our main research questions. This data set consists of all the contractual details of VC investments into 290 entrepreneurial firms and covers the period from 1990 to 2004 . We make use of various matching procedures to separate the selection effect from the pure $\mathrm{VC}$ type effect.

The fact that our data sample stems from the German VC market turns out to be very beneficial for our purpose. This particular market is, due to institutional reasons, populated by a rich variety of VC types with each type having a significant market share. This enables us to analyze firm selection and contract choice of different VC types properly on a broad enough data base with sufficient observations for most VC types. Moreover, it has the indirect effect that we are able to take a closer look on the differences in contractual design between the US - a fully developed VC market - and Germany - a yet immature but fast developing market - (see e.g. Bascha and Walz (2002) and Kaplan et al. (2003)) by asking to what degree the observed aggregate differences are due to a different structure of the respective VC markets as to their VC type composition.

The growing empirical research on venture capital issues normally limits to take into 
account a potential VC type effect (regarding contract design, investment behavior, active engagement as well as performance) by using different (often quite rough) dummy variables. Moreover, there also exist some papers which partially analyze the market segmentation between different types of VCs (see section 2 for details). Our matching approach points in the same direction, but goes one significant step beyond. Rather than only testing for the significance of such a VC type dummy, we are able to elaborate much further the details of such differences. We are able to explore in detail the very nature of these differences by identifying simultaneously the differences with respect to contract choice (which VC types use which particular aspect of the contract to what extent?) or the choice of firms (what type of firm with which characteristics is selected?). Thus we are able to give a comprehensive view about the differences between the VC types.

Our main findings are as follows. We find a crucial market segmentation between the different VC types (public VCs, bank-dependent VCs and independent VCs) which is mainly driven by the innovativeness of the project: the more innovative the entrepreneurial venture, the more probable is financing by an independent $\mathrm{VC}$ with respect to the other two VC types. This market segmentation seems to be influenced by potential strategic considerations of the VCs as well as the need of the VC's expertise by the entrepreneurial firm. Moreover, we find that for similar firms, the VC's corporate governance approaches differ significantly: independent VCs use significantly more contract mechanisms which induce active intervention than do bank-dependent VCs. They, in turn, use significantly more of these mechanisms than do public VCs. As concerns control mechanisms, these differences are less pronounced. This last result has important implications for crosscountry comparisons as it shows that observed differences in contract design may be rather due to differences in the market composition of the respective $\mathrm{VC}$ industries than to actual differences in the behavior of specific VC types.

The paper is organized as follows. In the next section, we provide a detailed literature review on (theoretical as well as empirical) research focusing in particular on the behavior of different VC types as well as on their differing objectives. In the third section, we develop a stylized model. We analyze the equilibrium behavior of three different VC types and derive testable hypotheses which form the basis for our subsequent empirical analysis. The data set which we use in our empirical investigation is described in the fourth section. The empirical method applied in our paper is discussed in the fifth section. The sixth section contains our empirical analysis in which we aim to address our leading questions. In the last section, we conclude. 


\section{Literature Review}

Our analysis is closely related to two branches of the literature: first, the literature which examines the different modes of venture capital financing focusing on the objectives and characteristics of different financiers and the matching between them and different types of firms; and second, the rather recent literature which empirically analyzes venture capital and private equity contracts. In what follows, we want to review these two strands of the literature.

Before looking into the main differences between VC types and the consequences on the governance of the financed ventures, it definitively helps to survey the main pros and cons of $\mathrm{VC}$ financing per se relative to other sources of financing for young firms - most notably banks. Studies analyzing this relationship typically start from the perception of VCs as being active (hands-on) investors which provide risk capital for entrepreneurial firms (see e.g. Landier (2004)). The more active involvement of VCs compared to e.g. bank financing is considered to be not only restricted to a more active engagement during the investment phase of the $\mathrm{VC}$ but also during the selection process. In this spirit, Berkovitch and Levy (2004) show within the framework of a search model that in market equilibrium, matching is partially mixed: venture capitalists may finance high and low added value projects while other financiers receive only low value added ones. Alike, Ueda (2004) develops a model of entrepreneurial finance where there exist two types of financiers: venture capitalists and banks. While venture capitalists are well informed, banks are not. But venture capitalists may appropriate the firm's idea while banks can not do that. Within this framework, she shows that projects financed through venture capitalists are larger and exhibit higher returns, higher growth and higher risk. In a similar way, Chemmanur and Chen (2003) investigate the choice between VC financing and angel financing. In their framework, VCs distinguish themselves not only by adding value to firms but also by possessing private information. They find that a separation of firms between angel and VC financing may occur only if neither of the two financing modes is very scarce. If this is not the case, however, i.e. if one source of financing is in very short supply, different types of firms seek and receive the respective alternative source of financing. In addition, they show that a particular firm may receive capital from different sources (angel and VC) over its life time.

In all these studies, venture capitalists are to be considered independent venture capitalists which only aim to maximize their monetary returns net of costs. There are, however, VC types which - with respect to their governance as well as with regard to their objectives - differ from this prototype of an independent VC. We can differentiate three types of VCs other than independent VCs: corporate VCs (or sometimes referred to as captive VCs (see Hellmann (2002)), i.e. VC firms owned by a strategic investor), bank-dependent VCs (owned by a bank), and public VCs (financed mainly with public money). For our 
analysis, two questions are especially important when looking at these different types of VCs: What are the main motives of each specific type and when is it selected as source of financing?

Besides independent VCs, corporate VCs have attracted the most attention. They are considered to be significantly different from independent VCs with respect to their objectives. Indeed, despite the often highlighted differences in corporate VCs' objectives (see e.g. Birkinshaw et al. (2002)), there is a general agreement that these objectives fall into two categories, namely strategic and financial objectives (see Chesbrough (2002) and Siegel et al. (1988)). Gompers and Lerner (2000) - who have been among the first who have studied corporate VCs by comparing them to independent VCs - show that the strategic interest of corporate VCs in their portfolio firm has some advantages but also some costs. They find in their empirical analysis that corporate venture investments in entrepreneurial firms appear to be at least as successful as those backed by independent venture organizations. Their data further indicates that corporate investments are made at a premium reflecting the indirect benefits of the strategic complementarities between the strategic investor and the portfolio firm. Building on the idea of complementarities between the entrepreneurial firm and the corporation backing the VC, Hellmann (2002) shows in his model that if the new venture is a complement (substitute) the entrepreneur selects the corporate (independent) $\mathrm{VC}^{1}$. He also points out that the choice of the $\mathrm{VC}$ type has a significant effect on the relationship and the general design of the contract between the new venture and the VC. The same finding emerges from De Bettignies and Chemla (2003) who show that entrepreneurs end up with fewer shares and less control under corporate VC than under independent VC financing. In our theoretical model in the next section, we will use these insights as a starting point to analyze the relation between the choice of a specific VC type and the contractual design in more detail.

In contrast to this rather large body of literature, bank-dependent VCs have attracted only limited attention. The major exception is Hellmann et al. (2004). Their empirical analysis suggests that banking organizations use their VC subsidiary to build relationships which are in the long run beneficial for their lending activities. Therefore, bank-dependent VCs aim at financing those firms which are most likely to generate credit demand in the future. They show that bank-dependent VCs behave in a significantly different way than independent VCs. Bank-dependent VCs invest less often in early rounds and they engage more in larger deals what reflects their desire to invest in firms which are more close to a situation where they may demand loans.

Public VCs are typically closely related to promotional programs of governments to foster the development of young start-up companies. They play a significant role in the

\footnotetext{
${ }^{1}$ Riyanto and Schwienbacher (2001) argue that the corporation can increase the complementarities by financing the venture via the corporate VC.
} 
overall VC market (see e.g. OECD (1996)). Not only in Continental European countries, such as France, Belgium, Italy and Germany, but also in the $\mathrm{US}^{2}$ and in particular in Canada $^{3}$, the share of public VCs is significant. Secrieru and Vigneault (2004) display an exception to the general neglect of public VCs in the literature. They investigate the role of public VCs and ask for the optimal level of advice which should be provided by the public VC. Thereby, they also highlight potential motives for public engagement in this market: internalization of externalities arising from innovations, liquidity constraints of entrepreneurial firms, and the certification role of public venture capital programs (see also Lerner (2002) on this point). In similar spirit, Hirsch (2005) investigates the effects of public policy programs which aim at internalizing the external effects stemming from entrepreneurial innovations on contract design. She shows that the design of the public intervention scheme may have serious effects on contracting mechanisms between private agents and may even worsen the resulting allocation.

Rather than looking at the differences among the various forms of VC types, Tykvova and Walz (2005) take the differences for granted and examine the consequences of these differences on the portfolio firms and their performance. In an overall compa-rison of different VCs and the performance of their portfolio firms in the aftermath of the IPO, they show that there is indeed a significant difference in the post-IPO performance of firms backed by different VC types. With data from the newly emerging IPO market in Germany, they reveal that firms backed by independent VCs do significantly better in the post-IPO performance thereby indicating the possibility that in the young German VC market investors did not take the value-added effects of independent VCs fully into account ${ }^{4}$.

Finally, as mentioned, our paper is also related to the line of literature which empirically analyzes the design of $\mathrm{VC}$ contracts. By looking at the link between the organizational structure of VCs and the design of the contracts between a specific type of VC and its portfolio firms, our analysis can be seen as a further piece in this rather recent literature. Starting with the seminal paper of Kaplan and Strömberg (2003) who looked into the main structural elements of US VC contracts against the background of models of corporate finance, a number of papers have emerged which have extended this approach to specific aspects of VC contracts (see Kaplan and Strömberg (2004)) and with respect to international data sets (see e.g. Kaplan et al. (2003) and Lerner and Schoar (2005)). In two companion papers, we have analyzed specific elements of VC contracts on the basis of

\footnotetext{
${ }^{2}$ See Lerner (2002) for a comprehensive analysis of various public programs aiming at the venture capital markets and a discussion of their design.

${ }^{3}$ Vaillancourt (1997) shows that more than 40 percent of venture capital in Canada in 1994 was managed by public VCs.

${ }^{4}$ In a related study, Rindermann (2005) analyzes the performance of firms before and around the IPO with a European data sample.
} 
a detailed and highly representative data sample from Germany (which is also used in this paper). Bienz and Hirsch (2005) look into the structure and determinants of staged VC contracts by - among other things - contrasting round financing with milestone financing. Bienz and Walz (2005) analyze the determinants of control and decision rights in VC contracts. In all these papers, however, VC types enter, if at all, at most as a dummy on the right-hand-side of the regression. In contrast, we take a much more elaborate look on the choice of VC types by firms and its implications on contract design, thereby representing a complementary view to the above papers.

\section{A Theoretical Analysis}

The aim of this section is to develop a stylized model which allows us to discuss the selection of VCs by portfolio firms as well as the resulting contractual designs in the respective relationships. We build our model on the stylized facts from the mentioned literature, i.e. the differences in the objectives and characteristics between VC types. This procedure allows us to explain the observed market segmentation and derive, at the same time, the determinants of the resulting contractual designs.

We allow for three different types of VCs endowed with funds to finance the projects of three different types of firms. As to the VCs, we distinguish - with regard to our empirical analysis - independent VCs (IVCs), bank-dependent VCs (BVCs) and public VCs (PVCs). The VC types differ with respect to their ability to provide advice for the firms and to monitor them. We model both activities as a dichotomous variable. That is, $\operatorname{control} c$ may take two realizations, either $c=0$ (no control) or $c=\bar{c}$ (control). The same holds true for advice $a$, i.e. $a \in\{0, \bar{a}\}$. PVCs do not have a technology to provide neither advice nor monitoring. Their respective costs are $C_{P V C}(\bar{c})=C_{P V C}(\bar{a})=\infty$. Independent VCs are specialized in both activities with cost functions $C_{I V C}(\bar{c})=k$ and $C_{I V C}(\bar{a})=e$. BVCs have prohibitive costs for providing advice $\left(C_{B V C}(\bar{a})=\infty\right)$ and their control technology is inferior to the one of IVCs but superior to the one of PVCs: $C_{B V C}(\bar{c})=\alpha k(\alpha>1)$.

There are three types of firms (or projects) which differ in their riskiness and the degree of innovation. We will refer to them as (in order of declining innovative- and riskiness) $\theta_{1}, \theta_{2}$, and $\theta_{3}$. All projects require funds $I$ in order to get started. In case of failure, all projects earn $\underline{\Pi}(\underline{\Pi}<I)$. Whereas profits are the same across projects in the case of failure, profits differ in the case of success. The more innovative the project is, the higher profits are in case of success: $\bar{\Pi}\left(\theta_{1}\right)>\bar{\Pi}\left(\theta_{2}\right)>\bar{\Pi}\left(\theta_{3}\right)$. The probabilities of success differ across projects, but are also dependent on the degree of monitoring and advice. Overall, we delineate the order of riskiness by assuming for the respective probabilities:

$$
p\left(\theta_{1}, \bar{a}, c\right)<p\left(\theta_{2}, a, \bar{c}\right)<p\left(\theta_{3}, a, c\right) \quad \forall a, c .
$$


For $\theta_{1}$-projects, advice is essential and control has, if advice is given to the firm, a positive impact, i.e. $p\left(\theta_{1}, \bar{a}, \bar{c}\right)>p\left(\theta_{1}, \bar{a}, 0\right)>p\left(\theta_{1}, 0, c\right)=0 \quad \forall c$. Moreover, we assume that the influence of additional control is limited: $p\left(\theta_{1}, \bar{a}, \bar{c}\right)-p\left(\theta_{1}, \bar{a}, 0\right) \leq p\left(\theta_{1}, \bar{a}, 0\right)$. For $\theta_{2^{-}}$ projects control is essential and advice has, if the firm is monitored, a positive impact, i.e. $p\left(\theta_{2}, \bar{a}, \bar{c}\right)>p\left(\theta_{2}, 0, \bar{c}\right)>p\left(\theta_{2}, a, 0\right)=0 \quad \forall a$. This additional impact is, however, smaller than for $\theta_{1}$-projects: $p\left(\theta_{1}, \bar{a}, \bar{c}\right)-p\left(\theta_{1}, \bar{a}, 0\right)>p\left(\theta_{2}, \bar{a}, \bar{c}\right)-p\left(\theta_{2}, 0, \bar{c}\right)$. For $\theta_{3}$-projects neither advice nor control increase the probability of success, i.e. $p\left(\theta_{3}, 0,0\right)=p\left(\theta_{3}, a, c\right)>$ $0 \forall a, c$.

PVCs and BVCs are able to extract additional indirect benefits from their engagement in the portfolio firms. While the BVCs are geared towards future credit business for their mother companies (see on this motivation Hellmann et al. (2004)), PVCs - due to their public mandate - aim at nonmonetary benefits from the venture (e.g. their ability to create jobs or to allow for (technology) spill-overs into other segments of the economy). In a nutshell, this implies that the total payoffs of the different VCs from their engagement in a particular firm $i$ can be written as:

$$
\Pi_{I V C}=p_{i} \bar{w}_{i}+\left(1-p_{i}\right) \underline{w}_{i}-k-e-I
$$

(in case the IVC monitors and provides advice) and

$$
\Pi_{B V C}=p_{i}\left(\bar{w}_{i}+B\right)+\left(1-p_{i}\right) \underline{w}_{i}-\alpha k-I
$$

(in case the BVC monitors but does not provide advice) and

$$
\Pi_{P V C}=p_{i} \bar{w}_{i}+\left(1-p_{i}\right) \underline{w}_{i}+P-I
$$

(in case the PVC does not provide neither advice nor monitoring) whereby $\underline{w}_{i}$ and $\bar{w}_{i}$ denote the monetary payoffs of the $\mathrm{VC}$ in the case of failure and success of the venture. We restrict these payoffs to positive levels. The indirect payoffs of the BVC only arise in the case of success (in which subsequent bank-financing is feasible) while the spill-over effect in the PVCs' objective function denoted by $P$ occurs in any case. We assume that for $\theta_{1}$ - and $\theta_{2}$-projects joint advice and control (even at the higher $\mathrm{BVC}$ costs of control) is socially beneficial, i.e.:

$$
\begin{gathered}
{\left[p\left(\theta_{1}, \bar{a}, \bar{c}\right)-p\left(\theta_{1}, \bar{a}, 0\right)\right]\left[\Pi\left(\theta_{1}\right)-\underline{\Pi}\right] \geq k} \\
p\left(\theta_{1}, \bar{a}, 0\right)\left[\bar{\Pi}\left(\theta_{1}\right)-\underline{\Pi}\right] \geq e \\
{\left[p\left(\theta_{2}, \bar{a}, \bar{c}\right)-p\left(\theta_{2}, 0, \bar{c}\right)\right]\left[\bar{\Pi}\left(\theta_{2}\right)-\underline{\Pi}\right] \geq e} \\
p\left(\theta_{2}, 0, \bar{c}\right)\left[\bar{\Pi}\left(\theta_{2}\right)-\underline{\Pi}\right] \geq \alpha k
\end{gathered}
$$


Obviously, given our above assumptions, it is optimal to neither exert control nor to provide advice for $\theta_{3}$-projects.

All projects, given optimal advice and monitoring activities (denoted by stars), are at least profitable. In addition we assume that $\theta_{1}$ - and $\theta_{2}$-projects are so profitable that their net social payoffs exceed $\underline{\Pi}$. That is:

$$
\begin{aligned}
{\left[1-p\left(\theta_{1}, \bar{a}, \bar{c}\right)\right] \underline{\Pi}+p\left(\theta_{1}, \bar{a}, \bar{c}\right) \bar{\Pi}\left(\theta_{1}\right)-I-e^{*}-k^{*} } & \geq \underline{\Pi} \\
{\left[1-p\left(\theta_{2}, \bar{a}, \bar{c}\right)\right] \underline{\Pi}+p\left(\theta_{2}, \bar{a}, \bar{c}\right) \bar{\Pi}\left(\theta_{2}\right)-I-e^{*}-k^{*} } & \geq \underline{\Pi} \\
{\left[1-p\left(\theta_{3}, 0,0\right)\right] \underline{\Pi}+p\left(\theta_{3}, 0,0\right) \bar{\Pi}\left(\theta_{3}\right)-I } & \geq 0
\end{aligned}
$$

In addition, we impose two technical assumptions

$$
\begin{gathered}
\frac{p\left(\theta_{1}, \bar{a}, 0\right)\left[p\left(\theta_{1}, \bar{a}, \bar{c}\right)-p\left(\theta_{1}, \bar{a}, 0\right)\right]}{\left[p\left(\theta_{2}, \bar{a}, \bar{c}\right)-p\left(\theta_{2}, 0, \bar{c}\right)\right] p\left(\theta_{2}, 0, \bar{c}\right)-p\left(\theta_{1}, \bar{a}, 0\right)\left[p\left(\theta_{1}, \bar{a}, \bar{c}\right)-p\left(\theta_{1}, \bar{a}, 0\right)\right]}[I-\underline{\Pi}] \leq k \leq \\
\frac{\left[p\left(\theta_{1}, \bar{a}, \bar{c}\right)-p\left(\theta_{1}, \bar{a}, 0\right)\right]^{2}}{p\left(\theta_{2}, 0, \bar{c}\right)}\left[\bar{\Pi}\left(\theta_{1}\right)-\underline{\Pi}\right]
\end{gathered}
$$

$$
\begin{aligned}
& \Pi\left(\theta_{1}\right)-\underline{\Pi} \geq \\
& \frac{p\left(\theta_{1}, \bar{a}, 0\right) p\left(\theta_{2}, 0, \bar{c}\right)}{\left[\left(p\left(\theta_{2}, \bar{a}, \bar{c}\right)-\left(p\left(\theta_{2}, 0, \bar{c}\right)\right]\left(p\left(\theta_{2}, 0, \bar{c}\right)-\left[p\left(\theta_{1}, \bar{a}, \bar{c}\right)-p\left(\theta_{1}, \bar{a}, 0\right)\right] p\left(\theta_{1}, \bar{a}, 0\right)\right]\right.\right.} \\
& \frac{1}{\left[\left(p\left(\theta_{1}, \bar{a}, \bar{c}\right)-p\left(\theta_{1}, \bar{a}, 0\right)\right]\right.}[I-\underline{\Pi}]
\end{aligned}
$$

The sequence of decisions is as follows.

- In the first stage, nature decides on the project type and the entrepreneur finds out about the type of his own project.

- In the second stage, the different VC types simultaneously offer contracts to the entrepreneur. In each group of VCs, perfect competition prevails.

- The third stage is characterized by the entrepreneurs' choices of the VC types and the contracts as well as by the VCs investing I.

- In stage 4, the VCs learn about the project type.

- Afterwards, in stage 5, they choose their effort levels.

- And, in stage 6, the projects pay off a certain level of cash flow and the contracts will be realized.

We will focus in the following on contracts which emerge from a separating set-up (i.e. firms never choose contracts designed for other firms) in which the VCs earn zero profits 
(due to competition). We concentrate on first-best results and ask whether these contracts actually do form a separating equilibrium. In addition, we investigate - in cases where these optimal contracts do not result - whether another separating perfect Bayesian equilibrium may arise and how it looks like. Throughout our entire discussion we concentrate only on contracts which lead to zero-profits for VCs. Given competition in the second stage of the game (and given that we do not want to derive the entire universe of potential equilibria, but rather want to focus on whether particular contracts are equilibrium contracts), this is rather straightforward. To be more precise, using the profit functions of the VCs (see eqs. (2), (3), and (4)) we get the following payoff structures:

$$
\begin{gathered}
\bar{w}\left(\theta_{i}\right)_{I V C}=\frac{k^{*}+e^{*}+I-\left[1-p\left(\theta_{i}, a_{i}^{*}, c_{i}^{*}\right)\right] \underline{w}\left(\theta_{i}\right)_{I C V}}{p\left(\theta_{i}, a_{i}^{*}, c_{i}^{*}\right)} \\
\bar{w}\left(\theta_{i}\right)_{B V C}=\frac{\alpha \cdot k^{*}+I-\left[1-p\left(\theta_{i}, 0, c_{i}^{*}\right)\right] \underline{w}\left(\theta_{i}\right)_{B V C}}{p\left(\theta_{i}, 0, c_{i}^{\alpha}\right)}-B \\
\bar{w}\left(\theta_{i}\right)_{P V C}=\frac{I-\left[1-p\left(\theta_{i} 0,0\right)\right] \underline{w}\left(\theta_{i}\right)_{P V C}-P}{p\left(\theta_{i}, 0,0\right)}
\end{gathered}
$$

whereby the stars denote the efficient levels of advice and control efforts and costs.

Against the background of this focus, we find the following for the fifth stage of our game (in stage six only nature moves). Note that $w\left(\theta_{i}\right)_{I V C}$ is the return the IVC has demanded in the case of contracts designed for $\theta_{i}$-projects.

\section{Lemma 1}

1) For $\theta_{1}$-projects:

i) BVCs and PVCs will always choose $a=0=c$ independent of contract design.

ii) For an IVC choosing $c=\bar{c}$ and $a=0$ for $\theta_{1}$-projects never pays off. IVCs will provide advice (even without monitoring) for $\theta_{1}$-projects having chosen $\theta_{m}$-contracts $(m \in[1,2])$ if $\underline{w}\left(\theta_{m}\right)_{I V C} \leq I+k+e-\frac{p\left(\theta_{m}, \bar{a}, \bar{c}\right)}{p\left(\theta_{1}, \bar{a}, 0\right)}$ e prevails. The IVC monitors the firm (in the presence of the provision of advice) if $\underline{w}\left(\theta_{m}\right)_{I V C} \leq$ $I+k+e-\frac{p\left(\theta_{m}, \bar{a}, \bar{c}\right)}{p\left(\theta_{1}, \bar{a}, \bar{c}\right)-p\left(\theta_{1}, \bar{a}, 0\right)} k$. If monitoring pays, providing advice is always worthwhile.

2) For $\theta_{2}$-projects

i) BVCs always choose $a=0$ and $c=\bar{c}$. PVCs always opt for $a=0=c$.

ii) IVCs will monitor (in the absence of advice) if $w\left(\theta_{2}\right)_{I V C} \leq I+k+e-\frac{p\left(\theta_{2}, \bar{a}, \bar{c}\right)}{p\left(\theta_{2}, 0, \bar{c}\right)} k$ in case a $\theta_{2}$-project has chosen the contract designed for its type. If it has selected 
a contract designed for $\theta_{1}$-projects, the IVC will always monitor. The IVC will provide advice (in the presence of control activities) for $\theta_{2}$-projects having chosen $\theta_{m}$-contracts if $w\left(\theta_{m}\right)_{I V C} \leq I+k+e-\frac{p\left(\theta_{m}, \bar{a}, \bar{c}\right)}{p\left(\theta_{2}, \bar{a}, \bar{c}\right)-p\left(\theta_{2}, 0, \bar{c}\right)}$. If providing advice pays for $\theta_{2}$-projects with $\theta_{m}$-contracts monitoring is always pay-off increasing for the IVC.

3) For $\theta_{3}$-projects all $V C$ types will always choose $a=0=c$ independent of contract design.

Proof 1 See Appendix.

With the help of Lemma 1, we can now address the main part of the model, namely the selection of VCs and contracts by the entrepreneurs. As already mentioned, we focus on the existence of a separating equilibrium and derive conditions under which such a separating equilibrium emerges and show how it precisely looks like. We state for the equilibrium of stage three of the game:

\section{Proposition 1}

1) $\theta_{1}$-projects will always choose to be financed by an IVC anticipating active advice and control.

2) i) $\theta_{2}$-projects may either select an IVC or a $B V C$.

ii) With $e \leq e_{1}$ and $\alpha \leq \alpha_{1}, \theta_{2}$-projects are financed by a $B V C$ anticipating active control but no advice.

iii) With $e \leq e_{1}$ and $\alpha>\alpha_{1}, \theta_{2}$-projects select an IVC anticipating active control and advice.

iv) With $e>e_{1}$ and $\alpha \leq \alpha_{2}, \theta_{2}$-projects select an $B V C$ anticipating control but no advice.

v) With $e>e_{1}$ and $\alpha>\alpha_{2}, \theta_{2}$-entrepreneurs select an IVC anticipating control but no advice.

3) $\theta_{3}$-projects will always select a PVC for their financing needs anticipating neither advice nor control.

whereby $\alpha_{1} \equiv 1+\frac{p\left(\theta_{2}, 0, \bar{c}\right) \cdot B}{k}+\frac{e}{k}-\frac{p\left(\theta_{2}, \bar{a}, \bar{c}\right)-p\left(\theta_{2}, 0, \bar{c}\right)}{k}\left[\bar{\Pi}\left(\theta_{2}\right)-\underline{\Pi}\right] ; \quad e_{1} \equiv \frac{p\left(\theta_{2}, \bar{a}, \bar{c}\right)-p\left(\theta_{2}, 0, \bar{c}\right)}{p\left(\theta_{1}, \bar{a}, \bar{c}\right)-p\left(\theta_{1}, \bar{a}, 0\right)} k$, and $\alpha_{2}=1+\frac{p\left(\theta_{2}, 0, \bar{c}\right)}{k} B$.

Proof 2 See Appendix. 
That is, we have a clear separation of $\theta_{1}$ - and $\theta_{3}$-projects which are financed by IVCs and PVCs. Only with $\theta_{2}$-projects, we have two outcomes: these projects are either financed by an IVC or a BVC. In the latter case, it may happen that the contracts offered to $\theta_{2^{-}}$ projects are structurally (with respect to the implied provision of advice and monitoring) different (see Proposition 1, 2ii) and iii)) or the same (see Proposition 1, 2iv) and v)) .

Given this result, we can now turn to the contract design stage of the game. Perfect competition among the VCs in each group implies undercutting and leads to zero profits for the VC. Due to the binary nature of the cashflows stemming from the different projects, and the fact that there are no other contractable variables besides realized cashflows, the optimal contract(s) will entail potentially two different pay-off levels which are contingent on the realized cashflows. Let us delineate these cashflows in case of success (failure) of the projects by $\bar{w}\left(\theta_{i}\right)_{j}\left(\underline{w}\left(\theta_{i}\right)_{j}\right)$ whereby $\theta_{i}$ denotes the project type for which the contract is designed for while $j \epsilon$ (IVC, PVC, BVC) stands for the VC type offering the contract.

Using Proposition 1 we can state (and thereby justify our initial assumption):

\section{Proposition 2}

The different VC types will offer contracts which just break even. The wage structure (each implying potentially a continuum of contracts) is depicted in (14), (15), and (16).

Proposition 4.2 basically describes the zero-profit nature of the equilibrium contracts. The absolute values are determined by the need to create incentive-compatibility and to ensure that a separating equilibrium actually emerges. Since they are by and large irrelevant for our purposes, we have decided to shift this analysis and the related discussion in the Appendix (i.e. in the proof of Proposition 1).

Using our above results enables us to deduce general hypotheses (mainly by using Proposition 1) concerning the selection of VC firms by entrepreneurs and the design of the respective contracts. First of all, we have to note that PVCs will finance only $\theta_{3^{-}}$ projects and that these projects always choose PVCs. Second, we find that BVCs finance, if at all, $\theta_{2}$-projects. IVCs in contrast, may finance $\theta_{1}$ - as well as $\theta_{2}$-projects.

Therefore we can state our first hypothesis:

\section{Hypothesis 1}

We expect a selection effect in the sense that there exists a correlation between the innovativeness of the project and the financing by means of different $V C$ types. The least innovative projects are financed by PVCs. BVCs finance projects with an intermediate level of innovation. Finally, we expect that the higher the degree of innovation the more likely it is that these projects are financed by IVCs.

Furthermore, if we let control costs $k$ to stay constant across time (i.e. different stages of maturity of the VC market) and assume advice costs to vary with market maturity (the more mature the market, the lower $e$ ), we can state the following hypotheses: 


\section{Hypothesis 2}

In mature markets (i.e. with lower e) different VC types financing the same type of firms design different contracts for these firms (see Proposition 1, 2ii) and 2iii)).

\section{Hypothesis 3}

In less mature markets (i.e. with a higher e) different VC types financing potentially the same type of firms design the same type of contracts for these firms (see Proposition 1, 2iv) and $2 v)$ ).

\section{The Data Set}

\subsection{Sample and Sample Selection Issues}

Our analysis uses a proprietary, hand-collected data set from KfW based on contracts between VCs and their portfolio firms. KfW has a unique position in Germany's venture capital market: being Germany's largest promotional bank, it supports innovative firms by promoting the investment of the VCs. Although, in our sample, KfW never directly invests in any of the portfolio firms, it becomes indirectly involved in the venture capital deals in Germany. In order to obtain support from KfW, VCs have to apply by submitting the key details of their relationship with the portfolio firm, most notably, the term sheets, the business plans and the shareholder's agreements. By providing us with access to these documents, KfW gave us the unique opportunity to collect detailed information on the relationship between the $\mathrm{VC}$ and its portfolio firm based on actual contract data.

In order to reduce the very time-intensive task of collecting detailed information from the numerous documents to a manageable size, we drew a random sample of 300 portfolio firms ${ }^{5}$. We categorized each portfolio company into one of three classes with respect to their investment date (before 1998, between 1998 and 2000, and after 2000) and eight classes with respect to the program or program combination through which their VC investor was supported by KfW. This categorization was undertaken with the objective to achieve a balanced representation of the population. Table 1 gives an overview about our sample and the support programs considered. Unfortunately, the data for 10 portfolio companies could not be evaluated. Therefore, our random sample finally consists of 290 portfolio companies that were financed in 464 investment rounds between 1990 and 2004. In this study, we will limit to first rounds in order to focus on the choice of a specific VC type and the initial contract design and blind out temporal effects in contract design.

We are confident that we do not have any major bias in the selection of our sample

\footnotetext{
${ }^{5}$ We drew this sample out of the population of all portfolio firms that were financed by venture capitalists which, in turn, were supported by KfW via one of the programmes mentioned in table 1.
} 
for two reasons. Firstly, as we were responsible for the sample selection process ourselves, we ensured that no selection bias occurred via the provider of all our documents (KfW) by drawing a random sample of all VC financed portfolio companies supported by KfW. Secondly, KfW supported a large proportion of the population of all investments realized by the German venture capital industry in the time period under consideration ${ }^{6}$. This means that we have a representative sample of the German VC industry. One obvious selection bias which we were not able to circumvent is the fact that we are concentrating on one particular geographic region (Germany) and the associated venture capital market. To a lesser degree this is true for the time period. We take all this into consideration by interpreting our data sample as the description of a situation of a young and evolving venture capital market.

As concerns the process of data collection, for each investment round, we evaluated the company's balance sheet data and its business plan to get information with respect to the market position of the company and details about the financed project. Moreover, we took from the term sheet and the shareholder's agreement detailed information about the security design, the timing and conditions of the investment, the syndication of the investment, control and information rights of the venture capitalists and exit covenants. We translated this information into quantifiable variables. Finally, we complemented the data set with information about the venture capitalist supported by KfW. Overall, we gained a detailed picture of the control and information rights embedded in these contracts as well as of the characteristics of the entrepreneurial firm, the founder(s) and the venture capitalists involved.

As usual in this type of studies, we were confronted with the problem that not always all data were available. Thus the number of observations may vary depending on the variable studied. Typically, the amount invested and valuations were the most reliable variables whereas information on staging or investment memoranda were sometimes missing. Still, we do not see a systematic selection bias problem because there are several reasons for missing data. On the one hand, data may be missing for very young firms but, on the other hand, we often had also the most exhaustive term sheets for these firms.

\subsection{Variable Descriptions}

In what follows, we describe the data set in more detail and introduce the variables necessary for our regressions. Please note that all balance sheet data as well as exogenous factors such as the state of product development is information that is known to the $\mathrm{VC}$ and the entrepreneur before they sign the contract.

\footnotetext{
${ }^{6}$ According to BVK (2003a) and (2003b), there were 11854 seed, start-up and expansion deals by its members in the relevant time period; KfW supported almost 7100 deals of potential members. This implies a market coverage of approximately $60 \%$.
} 


\section{Firm Characteristics}

We have information about the project and the respective portfolio company. We observe the firm's industry and create a dummy variable GROWTH INDUSTRIES which takes value one if the firm is active in the life-science area, the internet industry or the IT/telecommunication branch. If the firm belongs to a traditional industry or another industry the dummy takes value zero.

Furthermore, we observe the firm's development stage in each financing round. First, we have information about the firm's development stage as defined by the German Venture Capital Association. We distinguish seed and start-up firms on the one hand, and expansion and later stage firms on the other hand: the dummy EARLY STAGE indicates whether the firm belongs to the first group or not. Second, we have balance sheet information from the year preceding the closing date of the corresponding financing round. We know whether the firm has an audited balance sheet (in this case the dummy AUDITED BALANCE SHEET takes value one); we observe the fixed asset ratio (FAR) that indicates the ratio of fixed assets to balance sheet total ${ }^{7}$; and we know whether the firm has reached its break-even point what is captured by the dummy BREAK EVEN. Third, we have information about the firm's achievements. We know whether the firm has finished its product tests; whether it already has a finished product; whether the firm holds any patents or if it even has reference customers. We create a dummy variable FINISHED PRODUCT which signals the existence of a product and gives us concrete information about the development stage of the firm.

Finally, we observe whether the firm already received financing from banks or other VCs prior to the observed investment round. More concretely, we define a dummy PREVIOUS OUTSIDE FINANCE that takes value one if the portfolio company has received bank, angel or other $\mathrm{VC}$ finance before the first round of $\mathrm{VC}$ financing we are looking at.

\section{VC, Entrepreneur and Investment Characteristics}

Second, we have information about the VC, the entrepreneur and the investment characteristics. We classify each VC according to his type into four categories named INTERNATIONAL INDEPENDENT VC, LOCAL INDEPENDENT VC, BANK-DEPENDENT VC and PUBLIC VC.

Moreover, we have information about the entrepreneurs running the portfolio firm. We

\footnotetext{
${ }^{7}$ As we have many missing values in our sample, we adopt the following procedure. For all firms in a first financing round, with an age of less than one year at the date of contracting, and an investment phase of seed or early, we set the fixed asset ratio to zero. If we lack information for higher rounds, we use the same ratio as in the round before. If this ratio is not available, we code both as missing values. Additionally, we do not resort to the preceding round in the case of second rounds where we coded the first round data to be zero.
} 
know if any of the founders has a $\mathrm{PhD}$ or higher degree of education, we observe whether any of the founders has a background in engineering or natural sciences and we know whether we face a repeat entrepreneur, i.e. someone who has already run a firm. This last aspect is captured by the dummy variable REPEAT ENTREPRENEUR.

Finally, we have information about the investment itself. We observe the year when the financing round is closed and define three time dummies. PERIOD 1 takes value one if the financing round is closed during the early period of relatively low venture capital activity, namely before 1998, PERIOD 2 if it is closed during the boom, i.e. between 1998 and 2000 and PERIOD 3 if it is closed after 2000 - a period of relative decline and reorganization of the venture capital industry. In addition, we observe the total amount invested, the financing instrument used and the timing of the investment.

\section{Contract Elements}

Most importantly, we were able to evaluate the contracts between the VC which was supported by KfW and its portfolio company. We focus on five major contracting elements which we quantify by creating the following variables. First, we create the variable INCENTIVE MECHANISM DEGREE. This variable measures the extent of incentives which the VC gets by means of the design of his cash-flow rights. Based on the theoretical literature on optimal security design in venture capital frameworks with a double-sided moral hazard problem (see, for example Casamatta (2003) or Schmidt (2003)), we define this variable in the following way: it takes value zero with nonstandard debt and pure debt, value 1 with debt-equity mixes where the debt component is larger than the equity component, value two with debt-equity mixes where the debt component is smaller than the equity component, value three with pure equity and equity with a liquidation preference, and value four with convertibles ${ }^{8}$.

Second, we observe the percentage of voting rights which are hold by the $\mathrm{VC}^{9}$. We create a further categorial variable VOTING RIGHTS which takes value zero if the VC does not hold any voting rights, value one for the interval $(0,25 \%)$, value two for $[25 \%$, $50 \%)$ and value three for $[50 \%, 100 \%]$. The intervals were formed on the basis of the specific thresholds which are necessary to be able to decide about different categories of firm affairs.

Third, we observe whether the VC holds veto rights or not. We distinguish operational and structural veto rights. OPERATIONAL VETO RIGHTS is a categorial variable which represents the sum of the veto rights that govern the entrepreneur's actions in the firm:

\footnotetext{
${ }^{8}$ For the rules of classification of the mentioned securities see table 3 .

${ }^{9}$ In case that the VC supported by KfW syndicates, the data for the following contract elements refer to the whole syndicate. We adopt this procedure because due to our understanding of the data set, we conjecture that he is the decisive VC.
} 
the veto right against changes in the firm's line of business, the veto against certain financial decisions such as capital expenditures or the use of derivative instruments, the veto against changes in the firm's head count and veto rights against other decisions, i.e. against lawsuits on behalf of the firm. STRUCTURAL VETO RIGHTS is the sum of the veto rights that secure the VC's position in the firm: the veto right against changes in the shareholder's agreement, the veto that forbids the firm's dissolution and the veto against changes in the firm's capital structure such as giving out new shares.

Finally, we define a dummy variable LIQUIDATION RIGHTS which takes value one if one of the following elements which gives the $\mathrm{VC}$ an exit option is observed: pure debt or non-standard debt, a put option or staging.

\section{Matching: A Discussion of Methodological Issues}

\subsection{Foundations}

We aim at analyzing whether different VC types pursue distinct corporate governance approaches. We cannot attribute, however, the observed differences in contract design directly to differences in the corporate governance approaches. This would only be the case if the group of firms which is financed by one VC type or another would be random. Though, throughout this paper, we assume that the choice of a specific VC type is the result of underlying utility maximization by the respective firm and thus the group of firms is rather actively selected. Consequently, econometric methods which allow identifying the real differences in the VC approaches are necessary. One such method is matching which we will apply in this study.

Our problem can be stated as follows (see Lechner (2002)): We consider a world with 4 different VC types (PVC, BVC, LIVC and IIVC) and we will refer to the financing by each VC type as one specific treatment D with $D \in\{P V C, B V C, L I V C, I I V C\}$. The potential outcomes in each treatment (in our case the contract design with financing by each specific VC type) are denoted by $\left\{Y_{P V C}, Y_{B V C}, Y_{L I V C}, Y_{I I V C}\right\}^{10}$. In order to answer our research question, we want to identify the differences in contract design between VC type i and VC type $\mathrm{j}$ for all firms financed by VC type $\mathrm{i}$. These pairwise average treatment effects on the treated are given by

$$
A T T=E\left[Y_{i}-Y_{j} \mid D=i\right]=E\left[Y_{i} \mid D=i\right]-E\left[Y_{j} \mid D=i\right] \text { for } i, j \in D, i \neq j
$$

However, as every firm is financed by only one VC type, only the first term is observed in the data. The second term is unobservable - we are confronted with a problem of missing

\footnotetext{
${ }^{10}$ This notation already assumes that the treatment choice of one firm does not have an influence on the outcome of the other firms (stable-unit-treatment-assumption). When we assume that the supply of funds by one specific VC type is not scarce, this assumption holds in our context.
} 
data. In order to overcome this problem, identifying assumptions are necessary. In the evaluation literature, different assumptions and therefore different econometric methods are used $^{11}$. One assumption is the unconfoundness assumption which requires that all confounding variables $\mathrm{X}$, i.e. all variables which jointly determine both the choice of a specific VC type and the contract design, are available in the data set. Formally, the unconfoundness assumption states that all potential treatment outcomes are independent of the $\mathrm{VC}$ choice for any given vector of confounding variables $\mathrm{X}^{12}$ :

$$
D \perp\left(Y_{P V C}, Y_{B V C}, Y_{L I V C}, Y_{I I V C}\right) \mid X
$$

This means that for firms which are equal with respect to all confounding variables the choice of a specific VC type is random and thus, the differences in contract design between different VC types can be attributed to their different corporate governance approaches.

In our context, contracts between the $\mathrm{VC}$ and the portfolio firm are written on the basis of the information available before contracting. This information certainly includes the market situation, but also firm characteristics such as the development stage, the financial situation or the industry of the firm. Finally, it may comprise information about the entrepreneur(s) of the firm. The same information should guide the firm when choosing a specific VC type. As our data set contains a large set of variables which describe these aspects, we think that it is rich enough to identify all confounding variables and thus to allow for the identification of possible differences in the corporate governance approaches of the VC types ${ }^{13}$. Given unconfoundness and using the law of iterated expectations, the average treatment effect on the treated can then be written as

$$
A T T=E\left[Y_{i} \mid D=i\right]-E\left[E\left[Y_{j} \mid D=j, X\right] \mid D=i\right]
$$

It is obvious that the main challenge continues to be the estimation of the second term. One possible estimation procedure is matching whose central idea is to simply compare the contract design between VC type $\mathrm{i}$ and $\mathrm{VC}$ type $\mathrm{j}$ for firms which are identical with respect to all confounding variables. Classifying the firms in different cells according to all characteristics which are reflected by the confounding variables may be infeasible, however: the larger the number of variables in $\mathrm{X}$ and the more values each variable can take, the more cells must be taken into account. Furthermore, if the sample is small, there may not be sufficient firms financed by VC type i or VC type $\mathrm{j}$ in each cell (see e.g. Ichino $(2002))$.

\footnotetext{
${ }^{11}$ See Frölich (2004) for a survey with respect to multiple treatments and Blundell and Costa Dias (2002) as concerns binary treatments.

${ }^{12} \mathrm{As}$ we are interested in the pairwise comparison of the treatments, it even suffices if this condition holds only for the respective subsamples which receive financing either by VC type i or by VC type $\mathrm{j}$.

${ }^{13}$ See subsection 6.1 for more details.
} 
Rosenbaum and Rubin (1983) offer a possible solution to this dimensionality problem. They show (for the case of a binary treatment) that it is equivalent to condition on the propensity score instead of on all confounding variables. The propensity score is thereby defined as the conditional probability of receiving the treatment given $\mathrm{X}$ :

$$
p(X)=\operatorname{Pr}\{D=1 \mid X\}=E[D \mid X]
$$

This is true because the propensity score has two important properties. First, it balances the attributes $\mathrm{X}$, i.e. $D \perp X \mid p(X)$. This means that firms with the same propensity score have the same distribution of $\mathrm{X}$ independently of the choice of a specific $\mathrm{VC}$ type, and as the choice of a specific VC type is random, they are on average observationally equal. In turn, this implies that balancing may be achieved without controlling for all interactions of the single variables in $\mathrm{X}$ when estimating the propensity score. Second, if unconfoundness given X holds, then unconfoundness given $\mathrm{p}(\mathrm{X})$ holds as well. Imbens (2000) and Lechner (2001) generalize these results for the case of multiple treatments.

\subsection{Implementation}

Before being able to implement matching, some further steps are necessary. In a first step, the propensity scores have to be estimated provided that they are not already given in the data set. Lechner (2002) shows that in a multiple treatments framework, there exist two potential estimation strategies. First, binary conditional probabilities $\left(p^{i \mid i j}(X)\right)$ can be estimated for every subsample of firms financed by $\mathrm{VC}$ types $\mathrm{i}$ and $\mathrm{j}$ by using standard econometric methods as for example probit models. This procedure is relatively time-consuming because, for example in our case, already 6 different models have to be estimated. On the other hand, the pairwise estimation allows a flexible specification of the different models. The second estimation strategy consists in estimating a multinomial discrete-choice model in order to obtain $p^{i}(X) \forall i \in D$ and compute afterwards the conditional probabilities $p^{i \mid i j}(X)=\frac{p^{i}(X)}{p^{i}(X)+p^{j}(X)}$. As Lechner (2002) shows that the results do not differ systematically between the two strategies, we will adopt both estimation strategies in order to check our results for robustness.

In a second step, each treated observation has to be matched with untreated observations with the same propensity score and the conditional treatment effects need to be computed. In a last step, the average of these conditional effects must be determined with respect to the distribution of the propensity score for firms financed by VC type i (see Ichino (2002)). Though, in practice, this procedure may reveal two important problems.

First, it is quite improbable to find a treated and an untreated firm with exactly the same propensity score ${ }^{14}$. One possible solution may be to simply choose the nearest

\footnotetext{
${ }^{14}$ This is, in fact, the less probable, the more values the explaining variables can take.
} 
propensity score. In fact, this procedure is widespread and thus, we will use an adapted version in this paper, namely tied nearest neighbor matching with replacement. This method matches each treated observation with the nearest untreated observation in terms of propensity score and all further untreated observations with identical propensity score. Thereby, all matched observations are weighted equally. As nearest neighbor matching is implemented with replacement, each untreated observation may be used repeatedly ${ }^{15}$. However, nearest neighbor matching does not approach the trade-off between bias and variance inherent in matching: it minimizes the bias, but addresses the variance issue only afterwards by tied matching.

Therefore, in order to address this trade-off explicitly, we will also implement Gaussian kernel matching. With Gaussian kernel matching, the untreated observations are weighted inversely proportional to their distance from the respective treated observation in terms of the propensity score. This means that the second term of equation 17 is given by

$$
\frac{1}{N^{T}} \sum_{i \in T} \frac{\sum_{j \in C} Y_{j}^{C} G\left(\frac{p_{j}-p_{i}}{h}\right)}{\sum_{k \in C} G\left(\frac{p_{k}-p_{i}}{h}\right)}
$$

where $G(\cdot)$ is the Gaussian kernel function, $h$ represents the chosen bandwidth and $\mathrm{C}(\mathrm{T})$ refers to all the untreated (treated) observations. As can be seen in the equation, it is actually the choice of the bandwidth $h$ which aims at balancing bias and variance. There exist many methods to determine the optimal bandwidth. Silverman (1996), for example, derives a rule-of-thumb ( $h=0.9 \min$ [ standard deviation; interquartile range/1.34] $n^{-\frac{1}{5}}$ ) and shows that for a broad variety of underlying distributions, the so chosen bandwidth yields an integrated mean squared error which lies within $10 \%$ of the optimal one. As this result is convincing and the method can be easily implemented, we will use his rule to compute the bandwidths for the respective pairwise comparisons.

The second potential problem is the necessity of sufficient overlap between the propensity scores of firms financed by VC type i and $\mathrm{j}$. If this is not guaranteed, there may not exist adequate matches for some treated observations. One possible solution, which we will apply in our analysis, is to limit matching to the common support area. This means that all treated observations whose propensity score is higher than the maximum or lower than the minimum propensity score of the untreated observations are not considered. In this case, it is important to take into account that the ATT can be interpreted only as the average effect for those treated observations which fall in the common support area.

\footnotetext{
${ }^{15}$ This has the negative effect of inflating the variance, though it is necessary when handling multiple treatments with large differences in the number of observations for the particular treatments as it is the case in our data set (see Lechner (2002)).
} 


\section{Empirical Analysis}

When looking at table 4, we can observe crucial differences in contract design between the different VC types. There is a steady increase in the use of all analyzed contractual elements except liquidation rights when going from public VCs to bank-dependent VCs and further to independent VCs with an additional difference between local and international independent $\mathrm{VCs}^{16}$. As to liquidation rights, this order is slightly modified as public VCs hold in average more often some kind of liquidation right than bank-dependent VCs. Moreover, in this case, the differences are not always significant.

These descriptive statistics must be handled with precaution, however, as the differences cannot be directly ascribed to a different behavior of the various VC types. Thus it is necessary to have a closer look in order to disentangle the potential selection effect and the differences in the corporate governance approaches of the different VC types. Therefore, in a first step, we aim at identifying the determinants which influence the choice of a specific VC type, and in a second step, we will use different matching procedures in order to obtain the actual differences in contract design between the VC types.

\subsection{Do Different VCs Select Different Firms?}

As pointed out in section 5 , it is necessary to estimate conditional probabilities for the choice of each specific VC type (propensity scores) in order to be able to implement matching in a second step. At the same time, this procedure allows us to shed light on the selection issue. Hypothesis 1 states that there should exist a correlation between the innovativeness of the project and the financing by means of different $\mathrm{VC}$ types. This is expected to be the case due to the different needs of VC support by the entrepreneurs.

The specification of our regression models is driven by the search for the determinants which jointly influence VC choice and contract design. As remarked in section 5, we conjecture that these determinants should limit to information which is available to the entrepreneur or the VC before contracting. We classify this information into three groups: market situation, firm characteristics and track record. In order to control for the market situation, we will introduce the dummies for the early development of the industry (before 1998) and for the consolidation period (after 2001). With respect to firm characteristics, we think that we get a precise image by controlling for the development stage of the firm, its asset structure as well as its industry. And finally, as concerns the track record, we consider important to know if we are confronted with a repeat entrepreneur or if the firm

\footnotetext{
${ }^{16}$ The difference between public and bank-dependent VCs is, however, only significant in the case of the strength of the incentive mechanism, and the difference between local and international independent VCs is only significant in the case of the level of voting and veto rights. Moreover, with respect to operational veto rights, bank-dependent and local independent VCs do not show a significant difference.
} 
has already obtained outside financing before.

When specifying the different models, we have to balance the number of explanatory variables and the loss of observations due to missing values. This is especially true for our track record variables which show a relatively high amount of missing values. Therefore, we will only include them when the descriptive statistics suggest us to do so. Moreover, we have to avoid multicollinearity problems due to the use of highly correlated explanatory variables. This aspect is also important when deciding about the inclusion of our track record variables, especially the previous outside financing dummy. Finally, for the same reasons, we will use the finished product dummy as proxy for the development stage of the firm ${ }^{17}$. The estimation of the propensity scores by pairwise probit models gives us the flexibility to address these trade-offs for each model separately whereas with the multinomial model, we have to opt for one single specification - a reason why we exclude the track record variables.

Interpreting our descriptive statistics and our regression results (see tables 5, 7 and 8) gives us the following insights into market segmentation between the different VC types. Between the firms which are financed by public VCs are especially few firms which have obtained previous outside financing compared to all other VC types. For these firms, it may be especially difficult to get funding and thus, public VCs may prevent underinvestment. However, this seems to be the case only when no special expertise is necessary. In fact, public VCs finance significantly less firms in growth industries than do independent $\mathrm{VCs}^{18}$. These firms can be characterized by exhibiting a higher degree of uncertainty but also a higher innovation potential and therefore, a key role of strategic decisions which can be supported by the VC. The need for support is especially crucial if the entrepreneur has no expertise (i.e. is not repeat entrepreneur). Indeed, public VCs finance significantly less firms whose entrepreneur is not a repeat entrepreneur than international independent $\mathrm{VCs}^{19}$. So hypothesis 1 which states that less innovative projects should be financed by public VCs is confirmed. Moreover, the impact of the need of VC expertise on the choice of a specific VC type - as it is modelled in our framework in section 3 - is also confirmed. The same is true with respect to the importance of strategic objectives, such as the consideration of the spill-over effect to the rest of the economy by public VCs.

Bank-dependent VCs differ from the other VC types mainly in the fact that their firms present a significantly higher fixed asset ratio than the firms financed by all other VC types ${ }^{20}$. The fixed asset ratio can be interpreted as signal for the risk related to

\footnotetext{
${ }^{17}$ Other proxies would induce a higher loss of observations or a higher and therefore potentially problematic correlation with the fixed asset ratio (see table 6).

${ }^{18}$ With respect to international independent VCs, this difference is only significant in our descriptive statistics, however.

${ }^{19}$ This difference is, however, not robustly significant in our regressions.

${ }^{20}$ Interestingly, the fixed asset ratio is far from being significant in our regression results for the com-
} 
a specific investment: if the tangibility of assets is high and the $\mathrm{VC}$ has a liquidation preference, the probability of getting back his investment is relatively high. Moreover, bank-dependent VCs finance significantly less firms in growth industries than do independent $\mathrm{VCs}^{21}$. Analogously to the case of public VCs, we can again interpret this result as underlining the fact that bank-dependent VCs rather finance firms with a lower degree of uncertainty and a lower innovation potential and therefore a less pronounced need for $\mathrm{VC}$ support. Finally, the percentage of firms which have previously obtained outside financing is the highest with bank-dependent VCs - although the difference is only significant in our descriptive statistics in comparison with public and local independent VCs. Thus to sum up, we can say that hypothesis 1 is again broadly confirmed.

It is also interesting to look at the differences between local and international independent VCs. The only characteristic which differs significantly in both our descriptive statistics and our regression results is the fixed asset ratio - it is significantly lower for international independent VCs. But the descriptive statistics underline further - especially through the different means (though not significant) as well as through the comparison to public and bank-dependent VCs - that international independent VCs finance rather firms with a higher degree of uncertainty and a higher innovation potential, in earlier development stages and for whom their expertise is crucial.

Finally, there exist time effects of market segmentation which are shown in table 2: the percentage of firms financed by public and bank-dependent VCs drops approximately $50 \%$ from period 1 to period 3 whereas the percentage of local and international independent VCs almost reduplicated. As we include the period 1 and period 3 dummies in our regression, only the period 1 dummy is significant when comparing international independent VCs with public and bank-dependent VCs respectively. This is due to the fact that the percentage of international independent VCs quadruplicated from period 1 to the boom and then decreased again 50\% whereas the evolution of the percentage of all other VC types was continuous. Our model predicts that the higher the expertise of independent VCs (and therefore, the lower their costs), the higher should be the percentage of firms financed by independent VCs and the lower the percentage financed by bank-dependent VCs. This is just what we observe in table 2. Our model does not explain, however, the decrease in firms financed by public VCs. Nevertheless, when we proceed on the assumption that in period 1 , the financing of certain firms was not profitable without considering the spill-over effect to the rest of the economy due to the low level of expertise of the VCs but became profitable with the subsequent increase in expertise, this phenomenon can also be explained.

Thus to conclude, we can say that we observe a pronounced market segmentation parison with local independent VCs.

${ }^{21}$ With respect to international independent VCs, this difference is only significant at the $12 \%$ level. 
between the different VC types which depends crucially on the innovativeness of the projects. Hypothesis 1 is broadly confirmed: public VCs and bank-dependent VCs rather finance less innovative projects whereas the most innovative projects are financed by independent VCs. Moreover, we are able to identify the underlying driving factors for this kind of segmentation. Firstly, as in our model, the segmentation seems to be due to the differences in the objective functions (especially for public VCs) as well as the VC's capacity of providing the expertise needed by different firm types; and secondly, it is due to the maturation of the market.

\subsection{Do Different VCs Differ with Respect to Their Corporate Governance Approach?}

In order to be able to answer this question and test hypotheses 2 and 3, we have to disentangle the selection and the treatment effect. To do so, we will run two different matching procedures, namely tied nearest neighbor matching as well as Gaussian kernel matching - both with the common support restriction ${ }^{22}$. We base both methods on the two specifications of the propensity scores respectively: the propensity scores based on the pairwise probit models as well as the propensity scores based on the multinomial probit model. Thus, we will check our results for robustness with respect to the estimation strategy as well as the implemented matching method.

In order to give the most detailed description of the different corporate governance approaches, we will look at the key contract elements which can be classified - as in our model - into two groups : contract elements which allow/incentivize the VC to actively intervene in the firm - such as the strength of the incentive mechanism and the voting rights - and control rights, namely operational and structural veto rights as well as liquidation rights.

Before interpreting the matching results, it is important to assess the matching quality in order to justify the approach. Suitable indicators for the matching quality are the following. First, we should observe a substantial decrease in the pseudo- $R^{2}$ values from the unmatched to the matched sample, the pseudo- $R^{2}$ values resulting from a probit model for each of the two samples with the pairwise VC dummies as endogenous variables and the identified covariates (see, for example, Sianesi (2003)). In the same way, a sharp increase in the p-value of the likelihood ratio test testing for joint insignificance of all the covariates should be observed between the unmatched and matched sample in order to guarantee a good matching quality. And finally, a reduction of the median of the standardized bias following Rosenbaum and Rubin (1983) can also serve as a signal for the validity of the unconfoundness assumption. Tables 10 and 11 report these different

${ }^{22}$ See section 5 for details on the methods. 
measures for all the possible treatment and comparison group combinations which are indicated in column two. Moreover, they are reported for both matching methods (tied nearest neighbor matching (NN) and Gaussian kernel matching (GK), see column one). Finally, table 10 refers to the matching quality when using the propensity scores based on the pairwise probit models whereas table 11 refers to the matching quality when using the propensity scores based on the multinomial probit model.

When looking at these tables, we can observe that we generally achieve a substantial balancing of the confounding variables: the pseudo- $R^{2}$ diminishes considerably, the pvalue of the likelihood ratio test increases drastically and the median of the standardized bias following Rosenbaum and Rubin (1983) reduces sharply. When we look at table 10 at the category incentive mechanism degree, for example, we see that for local independent VCs as treatment group and bank-dependent VCs as control group, the pseudo- $\mathrm{R}^{2}$ before matching amounts to 0.105 and after matching it decreases to 0.005 with both matching methods; the p-value of the likelihood ratio test increases from 0.000 to 0.955 or 0.939 depending on the matching method. This means that the confounding variables are not able anymore to jointly explain the choice of a specific VC type what was, indeed, the objective of the matching procedure. Finally, the median of the standardized bias drops from 29.3 to 2.5 and 5.5 respectively. The last column indicates the loss of observations due to the common support restriction which is quite low in this case as only $1.73 \%$ of the observations are lost. Only in some cases, the achieved balancing is limited. This is especially the case when the percentage of observations lost due to the common support assumption is too high or the comparison group is substantially smaller than the treatment group (BVC vs. IIVC, LIVC vs. IIVC) or when the total number of observations in the pairwise comparison is relatively small (PVC vs. IIVC and BVC). In these cases, it is less probable to find adequate controls for the treated observations. As we interchange the treated and control units for each pairwise comparison in order to compare the corporate governance approaches for the two portfolios of firms financed by each VC respectively, in the majority of cases with limited balancing, we are anyhow able to get some insights - though only for one respective portfolio ${ }^{23}$.

Table 9 indicates the differences in the means of the single contracting elements before matching, i.e. before disentangling the selection and the treatment effect, and after matching which corresponds to the actual treatment effect. The change indicates the selection effect. As can be noted in the table, the differences in the corporate governance approaches often diminish significantly when controlling for the selection effect. However, they continue to be still substantial in various cases. When we look, for example, at voting rights and take international independent VCs as the treatment group and bank-dependent VCs

\footnotetext{
${ }^{23}$ As the results are broadly the same for both subgroups when balancing is achieved, we will not make this further distinction in what follows. Details about the differences can be seen in table 9 .
} 
as the control group, then we observe a significant difference in the mean of the categorial variable voting rights of 1.243. After matching, this difference reduces while remaining significant. To be more precise, it drops to 0.709 with tied nearest neighbor matching with the propensity scores based on the pairwise probit model, to 0.936 with Gaussian kernel matching and the mentioned propensity scores, to 0.783 with tied nearest neighbor matching with the propensity scores based on the multinomial probit model and finally, to 0.949 with Gaussian kernel matching and these last mentioned propensity scores. This means that the results are very robust indicating that for firms which are financed by international independent VCs, these VCs have significantly more voting rights than would have bank-dependent VCs financing these firms. Without controlling for the selection effect, this difference is even more pronounced what shows us that part of the observed difference in the behavior between these two $\mathrm{VC}$ types has to be attributed to selection effects whereas a substantial part actually ascribes to differences in the corporate governance approach. In what follows, we will therefore have a closer look at these differences for all the key contracting elements as well as the comparison of all VC types.

First, we will analyze the differences between public VCs and the other VC types. With respect to active intervention mechanisms as well as structural veto rights, we observe significant differences in the corporate governance approaches between public VCs and the other VC types whereby the latter one is less pronounced. On the contrary, for liquidation rights, these differences are not significant. As concerns operational veto rights, significance is only given for the differences between public VCs and independent VCs. Interestingly the differences between public and bank-dependent VCs tend to grow for intervention mechanisms after controlling for selection effects whereas there is hardly any change as concerns structural veto rights ${ }^{24}$. When comparing the contracts of public VCs with the contracts of local independent VCs, we remark a slight decline after matching with respect to active intervention mechanisms as well as to structural veto rights. As concerns operational veto rights, we get mixed results: for the firms financed by public VCs the differences tend to grow whereas for the firms financed by local independent VCs the differences tend to decrease. These results should be handled with precaution, however. Finally, when comparing the contracts of public VCs and international independent VCs, we get mixed results and so we are not able to evaluate the impact of the selection effect.

Second, we will analyze the differences between bank-dependent VCs and independent VCs. Here, we get very robust results: the differences between the different contract ele-

\footnotetext{
${ }^{24}$ It is important to take into account that the results based on the propensity scores of the multinomial probit model should be excluded because the propensity score has quite limited power in explaining the selection of a specific VC type. Moreover, due to the big loss of observations because of the common support restriction, the achievement of balancing is not convincing for the incentive mechanism degree for the comparison PVC vs. BVC when matching is based on the pairwise propensity scores.
} 
ments reduce substantially. After matching, differences are almost only significant for the active intervention mechanisms ${ }^{25}$.

Third, we will look at the differences between local and international independent VCs. There is no significant difference neither before nor after matching with respect to the strength of the incentive mechanism, operational veto rights as well as liquidation rights. But we observe significant differences with respect to structural veto rights and voting rights which even tend to grow after matching.

In addition, when looking into the details of our results, especially the distance of the corporate governance approaches between the different VC types, we get further interesting insights. As concerns active intervention mechanisms, the differences are the most pronounced whereby the bank-dependent VCs are situated nearly in between public VCs and local independent VCs. Local independent VCs get the same incentives but hold a significantly lower equity share than do international independent VCs. As concerns veto rights, we can state that most likely the public VC is the outlier: public VCs have significantly less veto rights than independent VCs and the difference between public and bank-dependent VCs is significant in the case of structural veto rights and higher though insignificant in the case of operational veto rights. Due to the small number of observations, these last results should be handled with precaution, however. In contrast, local independent and bank-dependent VCs do not behave in a significantly different way and only in a slightly different way than international independent $\mathrm{VCs}^{26}$.

Finally, if we interpret our empirical evidence against the background of our model, we gain the following insights. The model points out that differences only occur in equilibrium if the advice costs of independent VCs are sufficiently low. Thus, the observed differences in the design of the active intervention mechanisms should be interpreted as a signal of a relatively mature market. Moreover, in our model, active intervention as well as advice costs are modelled as dichotomous variables. Therefore, we find in our model only differences between independent VCs and the other VC types. If we interpret, however, our model more broadly by thinking of expertise and intervention levels as non-dichotomous variables, we can also explain the differences between public VCs and bank-dependent VCs. In addition, we may attribute the difference between local and international independent VCs to the higher expertise of international independent VCs (i.e. their lower advice costs) and therefore, their possibility to offer more differentiated contracts. With respect to control rights, our model only predicts a difference between public VCs and the other VC types due to the fact that the first ones are confronted with prohibitively high

\footnotetext{
${ }^{25}$ Note that the results with respect to control rights show sometimes significant differences, however, the results are not robust. Moreover, the differences are rather small.

${ }^{26}$ The differences between local and international independent VCs (and with some methods between bank-dependent and international independent) are only significant in the case of structural veto rights.
} 
costs of control. In our data, the major difference lies, indeed, between public VCs and the other VC types and we only observe differences between international independent VCs and local independent as well as bank-dependent VCs as to structural veto rights. If we again assumed a non-dichotomous variable for control effort, these differences could be easily explained, however.

To conclude, we think that this study has shown that the major difference between the different $\mathrm{VC}$ types does not lie in the handling of control rights but rather in the implementation of active intervention mechanisms. As expected, the involvement of the $\mathrm{VC}$ and therefore, the use of contract elements which guarantee this involvement, increases with the know-how of the VC. Speaking with the results of our model, these differences in the corporate governance approaches should be evaluated positively as they may be a signal for a high level of expertise of the independent VCs in the market.

\section{Conclusion}

The aim of the paper was to identify the causes of the observed differences in contract design between VC types, i.e. to disentangle firm selection effects and actual differences in the corporate governance approaches. Therefore, in a first step, we constructed a stylized model in which entrepreneurs choose a specific type of $\mathrm{VC}$ which, in turn, offers pooling or separating contracts. We then showed that, in equilibrium, VCs offer separating contracts, i.e. firm-type specific contracts, which may present differences in the corporate governance approaches or not. To be more precise, in our model, the most innovative projects are always financed by independent venture capitalists whereas the least innovative projects are financed by public VCs. As concerns the financing of projects with an intermediate level of innovativeness, however, they may be financed either by independent VCs or bankdependent VCs according to the cost structure of the latter ones. Thereby, the corporate governance approaches differ among the VC types for low effort costs of the VCs, i.e. in mature markets, but do not show any differences for higher effort costs, i.e. less developed VC markets.

In a second step, we analyzed these issues empirically using a hand-collected data set based on contract details between different VC types and their portfolio firms. We found that there exists a crucial market segmentation between the different $\mathrm{VC}$ types confirming our model: public VCs rather finance less innovative projects for which the need of VC expertise is low and for which it is especially difficult to obtain outside finance; bankdependent VCs also finance rather less innovative projects but, to the contrary, these firms exhibit low risk, i.e. their tangibility of assets is higher and more frequently, they obtained outside finance before. In contrast, independent VCs rather finance more innova- 
tive projects. In addition, we found that for similar firms, the VC's corporate governance approaches differ significantly: independent VCs use significantly more contract mechanisms which induce active intervention than do bank-dependent VCs which, in turn, use significantly more of these mechanisms than do public VCs. As far as control mechanisms are concerned, the differences are less pronounced for veto rights and nearly non-existent for liquidation rights.

To sum up, we can say that in Germany, VC types differ with respect to two aspects: on the one hand, they choose different kinds of firms but on the other hand, they also apply different corporate governance approaches. This result has important implications for further research and especially for the comparison of different VC markets as it shows that it is important to keep in mind the composition of the VC market. Indeed, one should compare the corporate governance approaches of one specific type of $\mathrm{VC}$ financing similar firms in both countries in order to identify the pure corporate governance differences and disentangle them from firm selection effects as well as market composition effects resulting from the different objective functions and characteristics of the $\mathrm{VC}$ types. When we compare the German and the US VC market, for example, we can observe strong differences in contract design between both countries. Though when confronting the contracts of German independent VCs with the US contracts (which are mainly of VCs operating independently), these differences are not crucial anymore. Thus, in this case, market composition effects seem to be much more important than actual VC effects. 


\section{References}

A. Bascha and U. Walz. Financing practices in the German venture capital industry: An empirical assessment. CFS Working Paper No. 2002/08, 2002.

E. Berkovitch and O. S. Levy. The choice between sources of financing and rate of return inequality. mimeo, 2004.

C. Bienz and J. Hirsch. The dynamics of venture capital contracts. Working Paper, 2005.

C. Bienz and U. Walz. Evolution of decision and control rights in venture capital contracts: An empirical analysis. Working Paper, 2005.

J. Birkinshaw, R. van Basten Batenburg, and G. Murray. Corporate Venturing: The state of the art and the prospects for the future. London Business School, Centre for the Network Economy, 2002.

R. Blundell and M. Costa Dias. Alternative approaches to evaluation in empirical microeconomics. Portuguese Economic Journal, 1:91-115, 2002.

C. Casamatta. Financing and advising: Optimal financial contracts with venture capitalists. Journal of Finance, 58:2059-2086, 2003.

T. Chemmanur and Z. Chen. Angels, venture capitalists, and entrepreneurs: A dynamic model of private equity financing. mimeo, 2003.

H. W. Chesbrough. Making sense of corporate venture capital. Harvard Business Review, pages $4-11,2002$.

J.E. De Bettignies and G. Chemla. Corporate venture capital: The upside of failure and competition for talent, 2003. mimeo.

M. Frölich. Programme evaluation with multiple treatments. Journal of Economic Surveys, 18:181-224, 2004.

P. Gompers and J. Lerner. The determinants of corporate venture capital success: Organizational structure, incentives, and complementarities. In Randall Morck, editor, Concentrated Ownership, pages 17-50. University of Chicago Press for the National Bureau of Economic Research, 2000.

T. Hellmann. A theory of strategic venture investing. Journal of Financial Economics, 64:285-314, 2002. 
T. Hellmann, L. Lindsey, and M. Puri. Building relationships early: banks in venture capital. Working Paper, 2004.

J. Hirsch. Public policy and venture capital financed innovation: A contract design approach. Working Paper, 2005.

A. Ichino. The problem of causality in the analysis of educational choices and labor market outcomes. Unpublished Slides for Lectures, 2002.

G. W. Imbens. The role of the propensity score in estimating dose response functions. Biometrika, 87:706-710, 2000.

S. Kaplan, F. Martel, and P. Strömberg. How do legal differences and learning affect financial contracts? Unpublished Working Paper, 2003.

S. Kaplan and P. Strömberg. Financial contracting theory meets the real world: An empirical analysis of venture capital contracts. The Review of Economic Studies, 70: 281-316, 2003.

S. Kaplan and P. Strömberg. Characteristics, contracts, and actions: Evidence from venture capitalist analyses. Journal of Finance, 59:2177-2210, 2004.

A. Landier. Start-up financing: From banks to venture capital. mimeo, 2004.

M. Lechner. Identification and estimation of causal effects of multiple treatments under the conditional independence assumption. In M. Lechner and F. Pfeiffer, editors, Econometric Evaluations Of Active Labor Market Policies in Europe. Physica/Springer, Heidelberg, 2001.

M. Lechner. Program heterogeneity and propensity score matching: An application to the evaluation of active labor market policies. The Review of Economics and Statistics, 84: 205-220, 2002.

J. Lerner. When bureaucrats meet entrepreneurs: The design of public venture capital programmes. Economic Journal, 112:F73-F84, 2002.

J. Lerner and A. Schoar. Transaction structures in the developing world: Evidence from private equity. Journal of Finance, forthcoming, 2005.

OECD. Government Programmes for Venture Capital. OECD, 1996.

G. Rindermann. The performance of venture-backed IPOs on Europe's new stock markets: Evidence from France, Germany and the UK. In G. Giudici and P. Roosenboom, editors, 
The Rise and Fall of Europe's New Stock Markets, Chap. 10, volume Vol. 10 of Advances in Financial Economics Series. Elsevier, 2005.

Y. Riyanto and A. Schwienbacher. On the strategic use of corporate venture finan-cing for securing demand. National University of Singapore, Working Paper, No. 0109, 2001.

P. R. Rosenbaum and D. B. Rubin. The central role of the propensity score in observational studies for causal effects. Biometrika, 70:41-55, 1983.

K.M. Schmidt. Convertible securities and venture capital finance. Journal of Finance, 58:1139-1166, 2003.

O. Secrieru and M. Vigneault. Public venture capital and entrepreneurship. Working Paper No. 2004-10, 2004.

B. Sianesi. Differential effects of Swedish active labour market programmes for unemployed adults during the 1990s. Working Paper Series W01/25, 2003.

R. Siegel, E. Siegel, and I.C. MacMillan. Corporate venture capitalists: autonomy, obstacles and performance. Journal of Business Venturing, 3:233-247, 1988.

B. W. Silverman. Density estimation for statistics and data analysis. Chapman \& Hall, London, 1996.

T. Tykvova and U. Walz. Are IPOs of different VCs different? mimeo, 2005.

M. Ueda. Banks versus venture capital: Project evaluation, screening, and expropriation. Journal of Finance, 59:601-621, 2004.

F. Vaillancourt. Labour-sponsored venture capital funds in Canada: Institutional aspects, tax expenditures, and employment creation. In P. Halpers, editor, Finan-cing Growth in Canada. Industry Canada Research Series, University of Calgary, 1997. 


\section{Appendix}

\subsection{Proof of Lemma 1}

$A d$ 1) i) Since advice is essential for $\theta_{1}$-projects and since $C(\bar{a})_{B V C}=C(\bar{a})_{P V C}=\infty$, neither PVCs nor BVCs will provide advice. Because $p\left(\theta_{1}, 0, c\right)=0 \quad \forall c$ monitoring does not pay either.

ii) For the IVC, it never pays to monitor without providing advice since $p\left(\theta_{1}, 0, c\right)=0 \quad \forall c$. However, providing advice (in the absence of monitoring) for $\theta_{1}$-projects which have chosen a $\theta_{m}$-contract may pay off for the IVC if

$$
\underline{w}\left(\theta_{m}\right)_{I V C}\left[1-p\left(\theta_{1}, \bar{a}, 0\right)\right]+\bar{w}\left(\theta_{m}\right)_{I V C} p\left(\theta_{1}, \bar{a}, 0\right)-I-e \geq \underline{w}\left(\theta_{m}\right)_{I V C}-I
$$

Inserting the proposed equilibrium pay-off structure for the IVC (see 14) and replacing $\bar{w}\left(\theta_{1}\right)_{I V C}$, we get the first inequality stated in 1ii) in Lemma 1.

Monitoring (with the simultaneous provision of advice) $\theta_{1}$-projects with $\theta_{m}$-contracts pays from the point of view of the IVC if

$$
\begin{gathered}
\underline{w}\left(\theta_{m}\right)_{I V C}\left[1-p\left(\theta_{1}, \bar{a}, \bar{c}\right)\right]+\bar{w}\left(\theta_{m}\right)_{I V C} p\left(\theta_{1}, \bar{a}, \bar{c}\right)-I-k-e \geq \\
\underline{w}\left(\theta_{m}\right)_{I V C}\left[1-p\left(\theta_{1}, \bar{a}, 0\right)\right]+\bar{w}\left(\theta_{m}\right)_{I V C} p\left(\theta_{1}, \bar{a}, 0\right)-I-e
\end{gathered}
$$

Note that if this condition holds, it is straightforward to show that providing advice always pays off. Inserting once again the proposed equilibrium pay-off structure for the IVC (see 14) and replacing $\bar{w}\left(\theta_{1}\right)_{I V C}$, we get the second inequality stated in 1ii) of Lemma 1.

$A d$ 2) i) Since $C(\bar{a})_{B V C}=\infty$, it never pays for the BVC to provide advice. Monitoring (in the absence of advice) $\theta_{2}$-projects pays off if

$$
\underline{w}\left(\theta_{2}\right)_{B V C}\left[1-p\left(\theta_{2}, 0, \bar{c}\right)\right]+\left[\bar{w}\left(\theta_{2}\right)_{B V C}+B\right] p\left(\theta_{2}, 0, \bar{c}\right)-I-\alpha k \geq \underline{w}\left(\theta_{2}\right)_{B V C}-I
$$

This is due to the zero profit-condition for the BVC always the case. Hence, BVCs will monitor $\theta_{2}$-firms but provide no advice.

Due to the infinite advice and monitoring costs PVCs do not provide neither advice nor monitoring.

ii) Monitoring (without advice) a $\theta_{2}$-project which is financed with a contract designed for a $\theta_{m}$-project is worthwhile for the IVC if:

$$
\left[1-p\left(\theta_{2}, 0, \bar{c}\right)\right] \underline{w}\left(\theta_{m}\right)_{I V C}+p\left(\theta_{2}, 0, \bar{c}\right) \bar{w}\left(\theta_{m}\right)_{I V C}-I-k \geq \underline{w}\left(\theta_{m}\right)_{I V C}-I
$$

Inserting the respective monetary returns of the IVC in the good state of nature and taking the zero-profit structure (for the respective contracts) of the IVC into account yields the first inequality depicted in the Lemma. 
Providing advice to $\theta_{2}$-projects (while simultaneously monitoring the firm) with a $\theta_{m}$-contract pays from the point of view of the IVC if

$$
\begin{gathered}
{\left[1-p\left(\theta_{2}, \bar{a}, \bar{c}\right)\right] \underline{w}\left(\theta_{m}\right)_{I V C}+p\left(\theta_{2}, \bar{a}, \bar{c}\right) \bar{w}\left(\theta_{m}\right)_{I V C}-I-k-e \geq} \\
{\left[1-p\left(\theta_{2}, 0, \bar{c}\right)\right] \underline{w}\left(\theta_{m}\right)_{I V C}+p\left(\theta_{2}, 0, \bar{c}\right) \bar{w}\left(\theta_{m}\right)_{I V C}-I-k}
\end{gathered}
$$

With the help of the zero-profit structure described in Proposition 2, we derive the last inequality of Lemma 1 . Note that if this condition holds, it is again straightforward to show that providing control always pays off.

Ad 3) Since $p\left(\theta_{3}, 0,0\right)=p\left(\theta_{3}, a, c\right) \quad \forall a, c$, it never pays to provide advice or monitor the projects.

\subsection{Proof of Proposition 1}

Ad 1) Only with an IVC, advice will be provided for $\theta_{1}$-projects. Given that advice is essential, $p\left(\theta_{1}\right)$ would be zero in all other cases. An entrepreneur with a $\theta_{1}$-project does not have an incentive to prefer a competitively priced BVC contract designed for $\theta_{2}$-projects against a competitively priced $\theta_{1}$-contract of an IVC if:

$$
\begin{array}{r}
{\left[1-p\left(\theta_{1}, \bar{a}, \bar{c}\right)\right] \underline{\Pi}+p\left(\theta_{1}, \bar{a}, \bar{c}\right) \bar{\Pi}\left(\theta_{1}\right)-I-k-e \geq} \\
\underline{\Pi}-\underline{w}\left(\theta_{2}\right)_{B V C}
\end{array}
$$

or if

$$
\underline{w}\left(\theta_{2}\right)_{B V C} \geq I+k+e-p\left(\theta_{1}, \bar{a}, \bar{c}\right)\left[\bar{\Pi}\left(\theta_{1}\right)-\underline{\Pi}\right]
$$

With respect to the PVC-selection, we get the corresponding condition:

$$
\underline{w}\left(\theta_{3}\right)_{P V C} \geq I+k+e-p\left(\theta_{1}, \bar{a}, \bar{c}\right) \cdot\left[\bar{\Pi}\left(\theta_{1}\right)-\underline{\Pi}\right]
$$

Ad 3) For a $\theta_{3}$-project, it never makes sense to monitor and provide advice independently of the chosen VC type (see Lemma 1). Given the additional mo-netary benefits, PVCs can grant higher remaining monetary payoffs for the $\theta_{3}$-entrepreneurs, namely:

$$
\left[1-p\left(\theta_{3}, 0,0\right)\right] \underline{\Pi}\left(\theta_{3}\right)+p\left(\theta_{3}, 0,0\right) \bar{\Pi}\left(\theta_{3}\right)-I+P
$$

In the proposed separating equilibrium the other VCs will design their contracts for the remaining two projects. To select these contracts does not make sense for $\theta_{3}$-projects for three reasons:

a) These contracts entail compensation for advice and for monitoring (see Lemma 1) which reduces the entrepreneurs payoffs. 
b) Since $p\left(\theta_{3}, 0,0\right)>p\left(\theta_{2}, a, \bar{c}\right)>p\left(\theta_{1}, \bar{a}, c\right) \quad \forall a, c$, the expected monetary reward for the $\mathrm{VC}$ will be higher if a $\theta_{3}$-project is financed with another contract.

c) Competition among PVCs will lead to the transfer of $P$ to the entrepreneurs. With the other VCs this transfer is smaller or non-existent.

Ad 2)

i) In equilibrium, $\theta_{2}$-projects are never financed by a PVC since a PVC would never monitor these projects (see Lemma 1 ) leading to $p\left(\theta_{2}, a, 0\right)=0$. Hence, the expected payoff of the entrepreneurs would - after taking the return of the PVC into account - read as:

$$
\underline{\Pi}-\underline{w}\left(\theta_{3}\right)
$$

Comparing this with a competitively supplied $\theta_{m}$-contract $(m=1,2)$ reveals (given our assumptions about the social return of the optimal $\theta_{m}$-projects which are assumed to be at least slightly larger than $\underline{\Pi}$ ) that it never makes sense to select a PVC.

ii) Comparing the optimally designed and competitively supplied contract for $\theta_{2}$-projects by an BVC with the one of an IVC we find that the payoff of the project with the former is larger than with the latter if (using Lemma 1)

$$
\begin{aligned}
& p\left(\theta_{2}, 0, \bar{c}\right)\left[\bar{\Pi}\left(\theta_{2}\right)+B\right]+\left[1-p\left(\theta_{2}, 0, c\right)\right] \underline{\Pi}-I-\alpha k \\
& \geq p\left(\theta_{2}, \bar{a}, \bar{c}\right) \bar{\Pi}\left(\theta_{2}\right)+\left[1-p\left(\theta_{2}, \bar{a}, \bar{c}\right)\right] \underline{\Pi}-I-k-e
\end{aligned}
$$

or

$$
\alpha \leq 1+\frac{e}{k}+\frac{B \cdot p\left(\theta_{2}, 0, \bar{c}\right)}{k}-\frac{p\left(\theta_{2}, \bar{a}, \bar{c}\right)-p\left(\theta_{2}, 0, \bar{c}\right)}{k}\left[\bar{\Pi}\left(\theta_{2}\right)-\underline{\Pi}\right] \equiv \alpha_{1}
$$

If that condition holds, the socially optimal contract entails the financing of $\theta_{2^{-}}$ projects by BVCs. From Lemma 1, we know that this implies $c=\bar{c}$ and $a=0$. This configuration is part of a separating equilibrium if $\theta_{2}$-projects do not have an incentive to choose a contract offered by IVCs designed for $\theta_{1}$-projects (Note that we showed in ad 1) that $\theta_{1}$-projects do never have an incentive to choose a BVC contract.). If $\theta_{2}$-entrepreneurs expect IVCs to monitor the firm but provide no advice (see Lemma 1), i.e. choose the same effort and control levels as BVCs it never pays to choose a $\theta_{1}$-contract from an IVC for analogous reasons as outlined above (see ad 3) arguments a-c). If it is anticipated that IVCs choose $a=\bar{a}$ and $c=\bar{c}$ (see Lemma 1 for the condition that this emerges) sticking with $\theta_{2}$-contracts 
of BVCs requires:

$$
\begin{array}{r}
p\left(\theta_{2}, 0, \bar{c}\right)\left[\bar{\Pi}\left(\theta_{2}\right)+B\right]+\left[1-p\left(\theta_{2}, 0, \bar{c}\right)\right] \underline{\Pi}-I-\alpha k \\
\geq p\left(\theta_{2}, \bar{a}, \bar{c}\right)\left[\bar{\Pi}\left(\theta_{2}\right)-\bar{w}\left(\theta_{1}\right)_{I V C}\right]+\left[1-p\left(\theta_{2}, \bar{a}, \bar{c}\right)\right]\left[\underline{\Pi}-\underline{w}\left(\theta_{1}\right)_{I V C}\right]
\end{array}
$$

With the zero-profit condition for the equilibrium $\theta_{1}$-contract we can rewrite this condition as

$$
\begin{aligned}
\underline{w}\left(\theta_{1}\right)_{I V C} \leq & I+k+\frac{p\left(\theta_{2}, \bar{a}, \bar{c}\right)}{p\left(\theta_{2}, \bar{a}, \bar{c}\right)-p\left(\theta_{1}, \bar{a}, \bar{c}\right)} \cdot e-\frac{p\left(\theta_{1}, \bar{a}, \bar{c}\right)}{p\left(\theta_{2}, \bar{a}, \bar{c}\right)-p\left(\theta_{1}, \bar{a}, \bar{c}\right)} \\
& {\left[(\alpha-1) k-p\left(\theta_{2}, 0, \bar{c}\right) B\right]-p\left(\theta_{1}, \bar{a}, \bar{c}\right) \frac{p\left(\theta_{2}, \bar{a}, \bar{c}\right)-p\left(\theta_{2}, 0, \bar{c}\right)}{p\left(\theta_{2}, \bar{a}, \bar{c}\right)-p\left(\theta_{1}, \bar{a}, \bar{c}\right)}\left[\bar{\Pi}\left(\theta_{2}\right)-\underline{\Pi}\right] }
\end{aligned}
$$

Inserting $\alpha_{1}$ into the above inequality allows us to rewrite this inequality as:

$$
\underline{w}\left(\theta_{1}\right)_{I V C} \leq I+k+e
$$

which is always fulfilled.

Hence, we have that with $\alpha \leq \alpha_{1}$ the contract offered by BVCs forms part of a separating equilibrium and has the following main property:

$$
I+k+e-p\left(\theta_{1}, \bar{a}, \bar{c}\right)\left[\bar{\Pi}\left(\theta_{1}\right)-I I\right] \leq \underline{w}\left(\theta_{2}\right)_{B V C} \leq \underline{\Pi}
$$

iii) With $\alpha>\alpha_{1}$ it is optimal to finance a $\theta_{2}$-project with an IVC. Such a setting displays a separating equilibrium if $\theta_{1}$-projects do not have an incentive to mimic $\theta_{2}$-projects and vice versa.

In case a $\theta_{1}$-project mimics to be a $\theta_{2}$-project and selects the IVC-contract designed for $\theta_{2}$-projects, three possibilities can arise. The IVC may choose a) $a=\bar{a}$ and $c=\bar{c}$, b) $a=\bar{a}$ and $c=0$ and finally c) $a=0=c$.

In case a) mimicking a $\theta_{2}$-project does not pay for $\theta_{1}$-entrepreneurs if:

$$
\begin{array}{r}
p\left(\theta_{1}, \bar{a}, \bar{c}\right) \bar{\Pi}\left(\theta_{1}\right)+\left[1-p\left(\theta_{1}, \bar{a}, \bar{c}\right)\right] \underline{\Pi}-I-k-e \\
\geq p\left(\theta_{1}, \bar{a}, \bar{c}\right)\left[\bar{\Pi}\left(\theta_{1}\right)-\bar{w}\left(\theta_{2}\right)_{I V C}\right]+\left[1-p\left(\theta_{1}, \bar{a}, \bar{c}\right)\right]\left[\underline{\Pi}-\underline{w}\left(\theta_{2}\right)_{I V C}\right] .
\end{array}
$$

Replacing $\bar{w}\left(\theta_{2}\right)_{I V C}$ with the help of the zero-profit conditions allows us to rewrite the above inequality as

$$
w\left(\theta_{2}\right)_{I V C} \geq I+k+e
$$

which can never hold.

Applying the same procedure to case b) yields the following condition:

$$
\underline{w}\left(\theta_{2}\right) \geq I+k+e-\frac{p\left(\theta_{2}, \bar{a}, \bar{c}\right)\left[p\left(\theta_{1}, \bar{a}, \bar{c}\right)-p\left(\theta_{1}, \bar{a}, 0\right)\right]}{p\left(\theta_{2}, \bar{a}, \bar{c}\right)-p\left(\theta_{1}, \bar{a}, 0\right)}\left[\bar{\Pi}\left(\theta_{1}\right)-\underline{\Pi}\right]
$$


In addition, we have to note that case $\mathrm{b}$ ) requires (for $a=\bar{a}$ and $c=0$ to emerge in case a $\theta_{1}$-project entrepreneur chooses a $\theta_{2}$-contract) that

$$
I+k+e-\frac{p\left(\theta_{2}, \bar{a}, \bar{c}\right)}{p\left(\theta_{1}, \bar{a}, \bar{c}\right)-p\left(\theta_{1}, \bar{a}, 0\right)} k \leq \underline{w}\left(\theta_{2}\right)_{I V C}<I+k+e-\frac{p\left(\theta_{2}, \bar{a}, \bar{c}\right)}{p\left(\theta_{1}, \bar{a}, 0\right)} \cdot e
$$

In addition, we need to have an incentive for IVCs to provide advice for $\theta_{2}$-projects with a $\theta_{2}$-contract (see Lemma 1$)$ :

$$
\underline{w}\left(\theta_{2}\right)_{I V C} \leq w\left(\theta_{m}\right)_{I V C}=I+k+e-\frac{p\left(\theta_{2}, \bar{a}, \bar{c}\right)}{p\left(\theta_{2}, \bar{a}, \bar{c}\right)-p\left(\theta_{2}, 0, \bar{c}\right)} \cdot e .
$$

Checking these conditions in detail, we find that the following two types of contracts are feasible

a) For $\frac{p\left(\theta_{2}, \bar{a}, \bar{c}\right)-p\left(\theta_{2}, 0, \bar{c}\right)}{p\left(\theta_{2}, 0, \bar{c}\right)}[k+(I-\underline{\Pi})] \leq e \leq \frac{p\left(\theta_{2}, \bar{a}, \bar{c}\right)-p\left(\theta_{2}, 0, \bar{c}\right)}{p\left(\theta_{1}, \bar{a}, \bar{c}\right)-p\left(\theta_{1}, \bar{a}, 0\right)} \cdot k$

$$
\begin{aligned}
I+k+e-\frac{p\left(\theta_{2}, \bar{a}, \bar{c}\right)}{p\left(\theta_{1}, \bar{a}, \bar{c}\right)-p\left(\theta_{1}, \bar{a}, 0\right)} k \leq & \underline{w}\left(\theta_{2}\right)_{I V C} \\
& \leq I+k+e-\frac{p\left(\theta_{2}, \bar{a}, \bar{c}\right)}{p\left(\theta_{2}, \bar{a}, \bar{c}\right)-p\left(\theta_{2}, 0, \bar{c}\right)} e
\end{aligned}
$$

b) For $e \leq \frac{p\left(\theta_{2}, \bar{a}, \bar{c}\right)-p\left(\theta_{2}, 0, \bar{c}\right)}{p\left(\theta_{2}, 0, \bar{c}\right)}[k+(I-\underline{\Pi})]$ :

$$
I+k+e-\frac{p\left(\theta_{2}, \bar{a}, \bar{c}\right)}{p\left(\theta_{1}, \bar{a}, \bar{c}\right)-p\left(\theta_{1}, \bar{a}, 0\right)} k \leq \underline{w}\left(\theta_{2}\right)_{I V C} \leq \underline{\Pi}
$$

This requires that in this case, a separating equilibrium only exists if

$$
e \leq \frac{p\left(\theta_{2}, \bar{a}, \bar{c}\right)-p\left(\theta_{2}, 0, \bar{c}\right)}{p\left(\theta_{1}, \bar{a}, \bar{c}\right)-p\left(\theta_{1}, \bar{a}, 0\right)} \cdot k \equiv e_{1}
$$

With case c) we get:

$$
\underline{w}\left(\theta_{2}\right) \geq I+k+e-p\left(\theta_{1}, \bar{a}, \bar{c}\right)\left[\bar{\Pi}\left(\theta_{1}\right)-\underline{\Pi}\right]
$$

This case requires (for $a=0$ and $c=0$ to emerge in case a $\theta_{1}$-project entrepreneur chooses a $\theta_{2}$-contract) that

$$
\underline{w}\left(\theta_{2}\right)_{I V C}>I+k+e-\frac{p\left(\theta_{2}, \bar{a}, \bar{c}\right)}{p\left(\theta_{1}, \bar{a}, 0\right)} e
$$

In addition, the above incentive compatibility condition for the optimal contract for $\theta_{1}$-projects has to hold.

Analyzing these three condition in detail reveals that they - due to $2 p\left(\theta_{1}, \bar{a}, 0\right)>$ $p\left(\theta_{1}, \bar{a}, \bar{c}\right)$ never hold simultaneously that is there does not exist a separating contract which induces $a=0=c$. 
It remains to investigate whether it pays for $\theta_{2}$-projects to pretend to be $\theta_{1}$-projects. Anticipating that the financing IVC chooses $a=\bar{a}$ and $c=\bar{c}$ for $\theta_{2}$-projects even if a contract designed for $\theta_{1}$-projects has been selected (see Lemma 1 for the relevant condition for this), it never pays for $\theta_{2}$-projects to pretend to be a $\theta_{1}$-project. Since $p\left(\theta_{2}, \bar{a}, \bar{c}\right)>p\left(\theta_{1}, \bar{a}, \bar{c}\right)$, the IVC would earn positive profits while with the $\theta_{2^{-}}$ contract, the IVC just breaks even. Since everything else is the same with a $\theta_{2^{-}}$and a $\theta_{1}$-contract, the former is definitely better than the latter for the entrepreneur.

Anticipating an equilibrium contract (i.e. one which just breaks even for the VC) in which the IVC with a $\theta_{2}$-project chooses $a=0$ and $c=\bar{c}$ we find that the $\theta_{2}$-project will not pick the $\theta_{1}$-project if:

$$
\begin{array}{r}
p\left(\theta_{2}, \bar{a}, \bar{c}\right) \bar{\Pi}\left(\theta_{2}\right)+\underline{\Pi}\left[1-p\left(\theta_{2}, \bar{a}, \bar{c}\right)\right]-I-k-e \geq \\
p\left(\theta_{2}, 0, \bar{c}\right)\left[\bar{\Pi}\left(\theta_{2}\right)-\bar{w}\left(\theta_{1}\right)_{I V C}\right]+\left[1-p\left(\theta_{1}, 0, \bar{c}\right)\right]\left[\underline{\Pi}\left(\theta_{2}\right)-\underline{w}\left(\theta_{1}\right)_{I V C}\right]
\end{array}
$$

Using the zero-profit condition gives us:

$$
\underline{w}\left(\theta_{1}\right)_{I V C} \leq I+k+e+\frac{p\left(\theta_{1}, \bar{a}, \bar{c}\right)\left[p\left(\theta_{2}, \bar{a}, \bar{c}\right)-p\left(\theta_{2}, 0, \bar{c}\right)\right]}{p\left(\theta_{2}, 0, \bar{c}\right)-p\left(\theta_{1}, \bar{a}, \bar{c}\right)}\left[\bar{\Pi}\left(\theta_{2}\right)-\underline{\Pi}\right]
$$

which always holds.

iv-v) As has been shown above, the optimal contract can only be a separating equilibrium if $e \leq e_{1}$. We now check whether with $e>e_{1}$, a second-best contract provided by an IVC with $a=0$ and $c=\bar{c}$ for $\theta_{2}$-projects may display a separating equilibrium.

Before we proceed and check whether such a contract provides a separating equilibrium we ask whether such a contract (i.e. a contract with no advice but control for $\theta_{2}$-projects) will be offered by an IVC or a BVC (note that the latter has been proven above to be a separating equilibrium already). In a competitive equilibrium, IVCs will provide the contract if:

$$
\begin{aligned}
p\left(\theta_{2}, 0, \bar{c}\right)\left[\bar{\Pi}\left(\theta_{2}\right)+B\right]+\left[1-p\left(\theta_{2}, 0, \bar{c}\right)\right] \underline{\Pi}-I-\alpha k \leq \\
p\left(\theta_{2}, 0, \bar{c}\right) \bar{\Pi}\left(\theta_{2}\right)+\left[1-p\left(\theta_{2}, 0, \bar{c}\right)\right] \underline{\Pi}-I-k
\end{aligned}
$$

or

$$
\alpha>\alpha_{2} \equiv 1+\frac{p\left(\theta_{2}, 0, \bar{c}\right) B}{k}
$$

If, however, $\alpha \leq \alpha_{2}$, BVCs will offer the contract.

We now proceed and ask whether the second-best contract offered by an IVC is actually an equilibrium.

In order to do this, we proceed in two steps. We first ask, whether the contract constitutes a separating equilibrium provided that the IVC (having offered a contract 
for $\theta_{2}$ which contains $a=0$ and $c=\bar{c}$ ) sticks to the announced no-advice case. In the second step, we ask whether the IVC indeed has an incentive to stick to the no-advice case for $\theta_{2}$-projects initially announced for these projects.

With respect to the first step, we can distinguish three subcases: the IVC financing a $\theta_{1}$-project with a $\theta_{2}$-contract chooses a) $a=\bar{a}$ and $c=\bar{c}$; b) $a=\bar{a}$ and $c=0$, and c) $a=0$.

We can immediately exclude the first situation as part of a separating equilibrium. In order to prevent that a $\theta_{1}$-entrepreneur chooses a $\theta_{2}$-project, the $\theta_{2}$ contract must fulfill the following condition:

$$
\underline{w}\left(\theta_{2}\right) \geq I+k+\frac{p\left(\theta_{2}, 0, \bar{c}\right)}{p\left(\theta_{2}, 0, \bar{c}\right)-p\left(\theta_{1}, \bar{a}, \bar{c}\right)} e
$$

which is never feasible.

In subcase b), the following conditions have to hold to make the proposed contract a separating equilibrium. First, for $\theta_{1}$-projects with a $\theta_{2}$-contract, choosing $a=\bar{a}$ (with $c=0$ ) and choosing $c=0$ must be in the interest of the IVC:

$$
\begin{gathered}
\underline{w}\left(\theta_{2}\right)_{I V C} \leq I+k-\frac{p\left(\theta_{2}, 0, \bar{c}\right)}{p\left(\theta_{1}, \bar{a}, 0\right)} e \\
\underline{w}\left(\theta_{2}\right)_{I V C} \geq I+k-\frac{p\left(\theta_{2}, 0, \bar{c}\right)}{p\left(\theta_{1}, \bar{a}, \bar{c}\right)-p\left(\theta_{1}, \bar{a}, 0\right)} k
\end{gathered}
$$

In addition, it must be guaranteed that $\theta_{1}$-projects do not choose $\theta_{2}$-contracts:

$$
\begin{aligned}
& \quad \underline{w}\left(\theta_{2}\right)_{I V C} \geq \\
& I+k+\frac{p\left(\theta_{2}, 0, \bar{c}\right)}{p\left(\theta_{2}, 0, \bar{c}\right)-p\left(\theta_{1}, \bar{a}, 0\right)} e-\frac{p\left(\theta_{2}, 0, \bar{c}\right)\left[p\left(\theta_{1}, \bar{a}, \bar{c}\right)-p\left(\theta_{1}, \bar{a}, 0\right)\right]}{p\left(\theta_{2}, 0, \bar{c}\right)-p\left(\theta_{1}, \bar{a}, 0\right)}\left[\Pi\left(\theta_{1}\right)-\underline{\Pi}\right]
\end{aligned}
$$

Finally, beside the limited liability condition $\left(\underline{w}\left(\theta_{2}\right)_{I V C} \leq \underline{\Pi}\right)$ the incentive compatibility condition for IVCs financing $\theta_{2}$-projects with $\theta_{2}$-contracts to provide no advice must hold:

$$
\underline{w}\left(\theta_{2}\right)_{I V C} \geq I+k-\frac{p\left(\theta_{2}, 0, \bar{c}\right)}{p\left(\theta_{2}, \bar{a}, \bar{c}\right)-p\left(\theta_{2}, 0, \bar{c}\right)} \cdot e
$$

An analysis of these conditions reveals that they can only hold simultaneously for $e \leq \frac{p\left(\theta_{1}, \bar{a}, 0\right)}{p\left(\theta_{1}, \bar{a}, \bar{c}\right)-p\left(\theta_{1}, \bar{a}, 0\right)} k$. That is, in this subcase, a separating equilibrium can only emerge when the IVC's costs are sufficiently low. Thereby, the corresponding contract is the following:

$$
I+k-\frac{p\left(\theta_{2}, 0, \bar{c}\right)}{p\left(\theta_{1}, \bar{a}, \bar{c}\right)-p\left(\theta_{1}, \bar{a}, 0\right)} k \leq \underline{w}\left(\theta_{2}\right)_{I V C} \leq I+k-\frac{p\left(\theta_{2}, 0, \bar{c}\right)}{p\left(\theta_{1}, \bar{a}, 0\right)} e
$$


In subcase c) (with $a=0$ chosen for $\theta_{1}$-projects choosing a $\theta_{2}$-contract), the respective conditions are

$$
\underline{w}\left(\theta_{2}\right)_{I V C} \geq I+k-\frac{p\left(\theta_{2}, 0, \bar{c}\right)}{p\left(\theta_{1}, \bar{a}, 0\right)} e
$$

the incentive compatibility condition for an IVC to provide $a=0$ for a $\theta_{1}$-project with a $\theta_{2}$-contract;

$$
\underline{w}\left(\theta_{2}\right)_{I V C} \geq I+k+e-p\left(\theta_{1}, \bar{a}, \bar{c}\right)\left[\bar{\Pi}\left(\theta_{1}\right)-\underline{\Pi}\right]
$$

the separation condition ensuring that $\theta_{1}$-entrepreneurs do not pick $\theta_{2}$-projects;

$$
\underline{w}\left(\theta_{2}\right)_{I V C} \geq I+k-\frac{p\left(\theta_{2}, 0, \bar{c}\right)}{p\left(\theta_{2}, \bar{a}, \bar{c}\right)-p\left(\theta_{2}, 0, \bar{c}\right)} e
$$

the incentive compatibility condition ensuring that IVCs actually choose $a=0$ for $\theta_{2}$-projects. Last but not least, we have to note the limited liability condition $\left(\underline{w}\left(\theta_{2}\right)_{I V C} \leq \underline{\Pi}\right)$.

Analyzing all these conditions reveals that it is always possible to meet them simultaneously. That is, a separating equilibrium will emerge with a contract that ensures that deviating $\theta_{1}$-firms have to expect $a=0$. The corresponding contract is the following

$$
\max \left[I+k-\frac{p\left(\theta_{2}, 0, \bar{c}\right)}{p\left(\theta_{1}, \bar{a}, 0\right)} e, I+k+e-p\left(\theta_{1}, \bar{a}, \bar{c}\right)\left[\bar{\Pi}\left(\theta_{1}\right)-\underline{\Pi}\right] \leq \underline{w}\left(\theta_{2}\right)_{I V C} \leq \underline{\Pi}\right.
$$

In the second step, we have to ask whether any deviations from the $\theta_{2}$-contract with $a=0$ and $c=\bar{c}$ as well as zero profits for the $\mathrm{VC}$ by choosing $a=\bar{a}$ in later stages may pay and may form an equilibrium. However, this setting can easily be dismissed as a candidate for an equilibrium with the following argument. Given that deviation from such a contract is profitable, i.e. it pays for the IVC to choose $a=\bar{a}$ this clearly implies positive profits for the IVC. In this case, however, IVCs, anticipating positive profits will undercut the initial contract by lowering either $\underline{w}\left(\theta_{2}\right)$ and/or $\bar{w}\left(\theta_{2}\right)$. In any case, the initial contract will be destroyed by the undercutting activities of the IVCs.

Hence, in a nutshell, we have shown that a second-best contract with $a=0$ and $c=\bar{c}$ for $\theta_{2}$-projects is a separating equilibrium for $e>e_{1}$ and will be provided by IVCs if $\alpha>\alpha_{2}$. In this case the separating equilibrium encompasses that the contract has to give an incentive for the IVC to choose $a=0$ for $\theta_{1}$-projects if they chose a $\theta_{2}$-project. For $e>e_{1}$ and $\alpha \leq \alpha_{2}$, BVCs will provide the $\theta_{2}$-contract with $a=0$ and $c=\bar{c}$. This contracts forms a separating equilibrium as well. 


\subsection{Tables}

Table 1: Sample Selection

\begin{tabular}{|l|cccc|}
\hline \hline & -1997 & $1998-2000$ & $2000-2004$ & Total \\
\hline \hline 1 & 51 & 102 & 22 & 175 \\
\hline 10 & 0 & 12 & 4 & 16 \\
\hline 11 & 0 & 8 & 1 & 9 \\
\hline 100 & 4 & 16 & 2 & 22 \\
\hline 1000 & 1 & 33 & 32 & 66 \\
\hline 1001 & 0 & 6 & 3 & 9 \\
\hline 1010 & 0 & 1 & 1 & 2 \\
\hline 1011 & 0 & 1 & 0 & 1 \\
\hline \hline Total & 56 & 179 & 65 & 300 \\
\hline \hline
\end{tabular}

Notes: 1 = Technology Participation Program (KfW/BMWA + KfW/BMTF - Technologie-Beteiligungsprogramm); $10=$ ERP-Innovation Program (ERP-Innovationsprogramm (Beteiligungsvariante)); $100=$ Guarantee Program (KfW-Risikokapitalprogramm - Garantien); $1000=$ Fund Program (KFW-Risikokapitalprogramm - Fondsfinanzierung); and mixes

Table 2: VC Types across Time Periods in Percent (\# Observations)

\begin{tabular}{||c||c|c|c|c|}
\hline \hline & Public VC & Bank-dep. VC & Local Ind. VC & Int. Ind. VC \\
\hline Complete Sample & $\begin{array}{c}13.43 \% \\
(38)\end{array}$ & $\begin{array}{c}28.27 \% \\
(80)\end{array}$ & $\begin{array}{c}43.11 \% \\
(122)\end{array}$ & $\begin{array}{c}15.19 \% \\
(43)\end{array}$ \\
\hline \hline Period 1 & $21.43 \%$ & $42.86 \%$ & $30.36 \%$ & $5.36 \%$ \\
& $(12)$ & $(24)$ & $(17)$ & $(3)$ \\
\hline \hline Period 2 & $11.18 \%$ & $25.88 \%$ & $43.53 \%$ & $19.41 \%$ \\
& $(19)$ & $(43)$ & $(74)$ & $(33)$ \\
\hline \hline Period 3 & $10.91 \%$ & $21.82 \%$ & $56.36 \%$ & $10.91 \%$ \\
& $(6)$ & $(12)$ & $(31)$ & $(6)$ \\
\hline \hline
\end{tabular}

Table 3: Summary Statistics I: Security Choice

\begin{tabular}{|c|c|c|c|c|c|c|c|c|c|}
\hline Category & \multicolumn{2}{|c|}{ Equity } & \multicolumn{2}{|c|}{ Debt \& Equity } & \multicolumn{3}{|c|}{ Convertibles } & \multicolumn{2}{|l|}{ Debt } \\
\hline Description & $\begin{array}{l}\text { Pure } \\
\text { Equity }\end{array}$ & $\begin{array}{l}\text { Equity } \\
+\mathrm{LP}\end{array}$ & $\begin{array}{l}\text { Debt }> \\
\text { Equity }\end{array}$ & $\begin{array}{l}\text { Debt }< \\
\text { Equity }\end{array}$ & US Style & $\begin{array}{c}\text { Convertible } \\
\text { Equity }\end{array}$ & Mixes & $\begin{array}{c}\text { Nonstandard } \\
\text { Debt }\end{array}$ & $\begin{array}{l}\text { Pure } \\
\text { Debt }\end{array}$ \\
\hline Category & 1 & 2 & 3 & 5 & 6 & 7 & 8 & 4 & 9 \\
\hline Upside Cash Flow Rights & $\mathrm{X}$ & $\mathrm{X}$ & $\mathrm{X}$ & $\mathrm{X}$ & $\mathrm{X}$ & $\mathrm{X}$ & $\mathrm{X}$ & $\mathrm{X}$ & - \\
\hline Downside Protection & - & $\mathrm{X}$ & $\mathrm{X}$ & - & $\mathrm{X}$ & $\mathrm{X}$ & $\mathrm{X}$ & $\mathrm{X}$ & $\mathrm{X}$ \\
\hline Change of Control & - & - & $\mathrm{X}$ & $\mathrm{X}$ & $\mathrm{X}$ & - & $\mathrm{X}$ & $\mathrm{X}$ & $\mathrm{X}$ \\
\hline Cash Flow Rights at Exit & $\mathrm{X}$ & $\mathrm{X}$ & $\mathrm{X}$ & $\mathrm{X}$ & $\mathrm{X}$ & $\mathrm{X}$ & $\mathrm{X}$ & - & - \\
\hline Voting Rights & $\mathrm{X}$ & $\mathrm{X}$ & $\mathrm{X}$ & $\mathrm{X}$ & - & $\mathrm{X}$ & $\mathrm{X}$ & - & - \\
\hline & 51 & 85 & 157 & 20 & 11 & 10 & 16 & 11 & 96 \\
\hline Total Percentage & \multicolumn{2}{|c|}{$29 \%$} & \multicolumn{2}{|c|}{$38 \%$} & \multicolumn{3}{|c|}{$8 \%$} & \multicolumn{2}{|l|}{$23 \%$} \\
\hline
\end{tabular}

Notes: We report the VC's security choice which is categorized according to the indicated five characteristics. We were confronted with 7 missing values. 
Table 4: The Usage of Key Contract Elements by Different VC Types

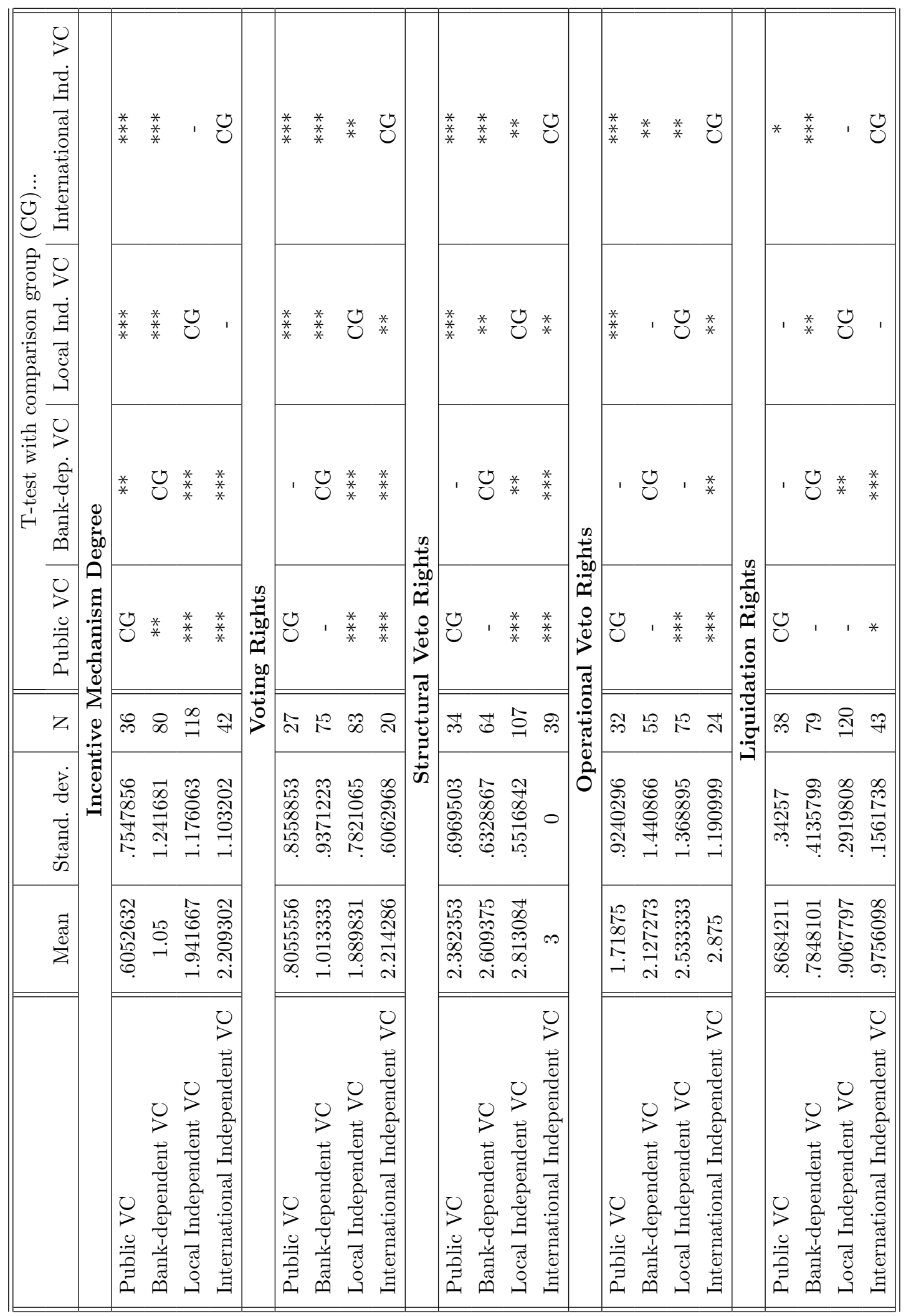


Table 5: The Characteristics of Firms Financed by the Different VC Types

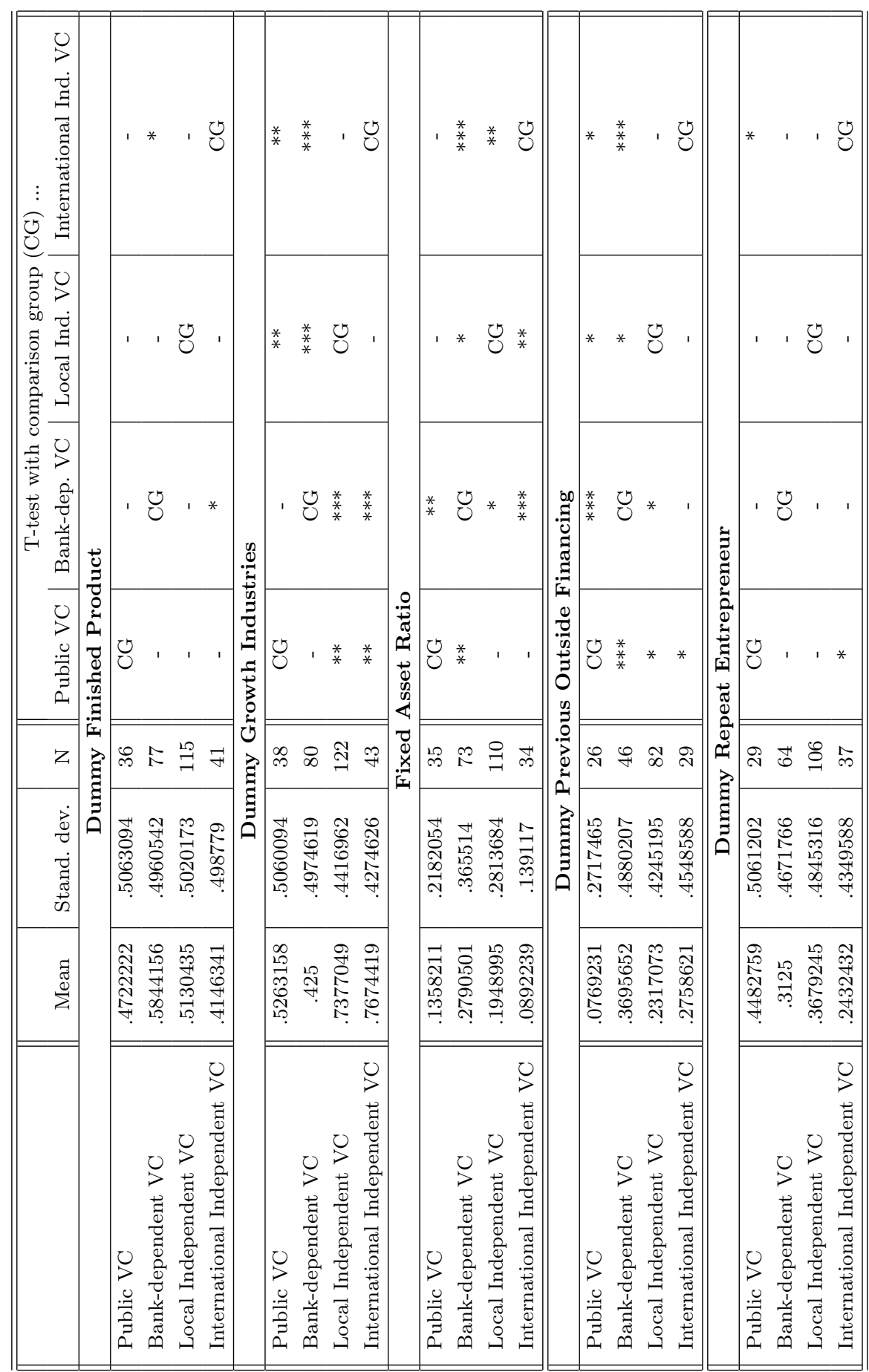


Table 6: Correlation Matrix for the Complete Sample and the Different Subsamples

\begin{tabular}{|c|c|c|c|c|c|c|c|}
\hline \multicolumn{8}{|c|}{ Different Proxies for Development Stage and Fixed Asset Ratio } \\
\hline & Early stage & Fin. prod. & Break Even & Aud. Bal. Sheet & FAR & & \\
\hline Early Stage & 1.0000 & & & & & & \\
\hline Finished Product & $-0.4164^{*}$ & 1.0000 & & & & & \\
\hline Break Even & $-0.5798 *$ & $0.3038 *$ & 1.0000 & & & & \\
\hline Audited Balance Sheet & $-0.4179^{*}$ & $0.4726^{*}$ & $0.4165^{*}$ & 1.0000 & & & \\
\hline Fixed Asset Ratio & $-0.2640^{*}$ & $0.2086^{*}$ & $0.2551^{*}$ & $0.4654^{*}$ & 1.0000 & & \\
\hline \multicolumn{8}{|c|}{$\begin{array}{c}\text { Correlations between the Variables Used } \\
\text { Complete Sample }\end{array}$} \\
\hline & Fin. prod. & FAR & Prev. Outs. Fin. & Rep. E & G. Ind. & P. 1 & P. 2 \\
\hline Finished Product & 1.0000 & & & & & & \\
\hline Fixed Asset Ratio & $0.2086^{*}$ & 1.0000 & & & & & \\
\hline Previous Outside Finance & $0.3135^{*}$ & $0.4419 *$ & 1.0000 & & & & \\
\hline Repeat Entrepreneur & -0.0060 & 0.0115 & 0.0521 & 1.0000 & & & \\
\hline Growth Industries & $-0.1911^{*}$ & $-0.1911 *$ & -0.1133 & -0.0396 & 1.0000 & & \\
\hline Period 1 & 0.0024 & 0.0623 & 0.0139 & $-0.1178 *$ & $-0.1291 *$ & 1.0000 & \\
\hline Period 3 & 0.0374 & 0.0554 & $0.1997^{*}$ & 0.0582 & 0.0220 & $-0.2420^{*}$ & 1.0000 \\
\hline \multicolumn{8}{|c|}{ Subsample Public VC - Bank-dep. VC } \\
\hline & Fin. prod. & FAR & Prev. Outs. Fin. & Rep. E & G. Ind. & P. 1 & P. 2 \\
\hline Finished Product & 1.0000 & & & & & & \\
\hline Fixed Asset Ratio & 0.1580 & 1.0000 & & & & & \\
\hline Previous Outside Finance & $0.4395^{*}$ & $0.4462 *$ & 1.0000 & & & & \\
\hline Repeat Entrepreneur & -0.0732 & 0.0267 & -0.0752 & 1.0000 & & & \\
\hline Growth Industries & -0.1423 & -0.0854 & $-0.2345^{*}$ & -0.1176 & 1.0000 & & \\
\hline Period 1 & -0.1215 & -0.0764 & 0.0243 & $-0.1773^{*}$ & 0.0194 & 1.0000 & \\
\hline Period 3 & 0.0060 & -0.0634 & 0.0243 & 0.0788 & 0.0834 & $-0.2811^{*}$ & 1.0000 \\
\hline \multicolumn{8}{|c|}{ Subsample Public VC - Local independent VC } \\
\hline & Fin. prod. & FAR & Prev. Outs. Fin. & Rep. E & G. Ind. & P. 1 & P. 2 \\
\hline Finished Product & 1.0000 & & & & & & \\
\hline Fixed Asset Ratio & $0.2792^{*}$ & 1.0000 & & & & & \\
\hline Previous Outside Finance & $0.2132 *$ & $0.4361 *$ & 1.0000 & & & & \\
\hline Repeat Entrepreneur & -0.1050 & -0.0918 & 0.0566 & 1.0000 & & & \\
\hline Growth Industries & -0.1107 & $-0.2116^{*}$ & 0.0435 & 0.0184 & 1.0000 & & \\
\hline Period 1 & -0.0030 & 0.1169 & 0.0188 & -0.0247 & $-0.1378^{*}$ & 1.0000 & \\
\hline Period 3 & 0.0732 & 0.0962 & $0.2566^{*}$ & -0.0384 & 0.0180 & $-0.2581^{*}$ & 1.0000 \\
\hline \multicolumn{8}{|c|}{ Subsample Public VC - International independent VC } \\
\hline & Fin. prod. & FAR & Prev. Outs. Fin. & Rep. E & G. Ind. & P. 1 & P. 2 \\
\hline Finished Product & 1.0000 & & & & & & \\
\hline Fixed Asset Ratio & $0.4135^{*}$ & 1.0000 & & & & & \\
\hline Previous Outside Finance & 0.1479 & $0.2627^{*}$ & 1.0000 & & & & \\
\hline Repeat Entrepreneur & 0.0104 & -0.1825 & 0.0649 & 1.0000 & & & \\
\hline Growth Industries & -0.0591 & $-0.2813^{*}$ & 0.0451 & -0.0899 & 1.0000 & & \\
\hline Period 1 & -0.1479 & 0.0517 & -0.0137 & 0.0539 & $-0.1881^{*}$ & 1.0000 & \\
\hline Period 3 & 0.0181 & 0.0332 & $0.2925^{*}$ & 0.0833 & 0.1056 & $-0.2084^{*}$ & 1.0000 \\
\hline \multicolumn{8}{|c|}{ Subsample Bank-dep. VC - Local independent VC } \\
\hline & Fin. prod. & FAR & Prev. Outs. Fin. & Rep. E & G. Ind. & P. 1 & P. 2 \\
\hline Finished Product & 1.0000 & & & & & & \\
\hline Fixed Asset Ratio & $0.1562 *$ & 1.0000 & & & & & \\
\hline Previous Outside Finance & $0.3613^{*}$ & $0.4676^{*}$ & 1.0000 & & & & \\
\hline Repeat Entrepreneur & -0.0359 & -0.0547 & -0.0504 & -1.0000 & - & - & - \\
\hline Growth Industries & $-0.2345^{*}$ & $--0.1938^{*}$ & $-0.1805^{*}$ & -0.0054 & -1.0000 & - & - \\
\hline Period 1 & 0.0519 & 0.0566 & 0.0044 & $-0.1930^{*}$ & -0.1054 & 1.0000 & \\
\hline Period 3 & 0.0428 & 0.0433 & $0.1596^{*}$ & 0.0537 & -0.0098 & $-0.2624^{*}$ & 1.0000 \\
\hline \multicolumn{8}{|c|}{ Subsample Bank-dep. VC - International independent VC } \\
\hline & Fin. prod. & FAR & Prev. Outs. Fin. & Rep. E & G. Ind. & P. 1 & P. 2 \\
\hline Finished Product & 1.0000 & & & & & & \\
\hline Fixed Asset Ratio & 0.1451 & 1.0000 & & & & & \\
\hline Previous Outside Finance & $0.4053^{*}$ & $0.4450^{*}$ & 1.0000 & & & & \\
\hline Repeat Entrepreneur & 0.0958 & 0.1425 & 0.0526 & 1.0000 & & & \\
\hline Growth Industries & $-0.2756^{*}$ & $-0.1718^{*}$ & $-0.2478^{*}$ & -0.1044 & 1.0000 & & \\
\hline Period 1 & -0.0056 & -0.0077 & 0.0305 & $-0.2604^{*}$ & -0.1068 & 1.0000 & \\
\hline Period 3 & 0.0008 & 0.0013 & 0.1414 & $0.2041^{*}$ & -0.0158 & $-0.2267^{*}$ & 1.0000 \\
\hline \multicolumn{8}{|c|}{ Subsample Local independent VC - International independent VC } \\
\hline & Fin. prod. & FAR & Prev. Outs. Fin. & Rep. E & G. Ind. & P. 1 & P. 2 \\
\hline Finished Product & 1.0000 & & & & & & \\
\hline Fixed Asset Ratio & $0.2653^{*}$ & 1.0000 & & & & & \\
\hline Previous Outside Finance & $0.2192 *$ & $0.4500^{*}$ & 1.0000 & & & & \\
\hline Repeat Entrepreneur & 0.0104 & -0.0052 & 0.1300 & 1.0000 & & & \\
\hline Growth Industries & $-0.2073^{*}$ & $-0.2767^{*}$ & -0.0210 & 0.0588 & 1.0000 & & \\
\hline Period 1 & 0.0895 & $0.1855^{*}$ & -0.0106 & -0.0912 & $-0.1666^{*}$ & 1.0000 & \\
\hline Period 3 & 0.0743 & $0.1614^{*}$ & $0.2992 *$ & 0.0552 & -0.0769 & $-0.2032^{*}$ & 1.0000 \\
\hline
\end{tabular}

Notes: Pairwise correlations are indicated. * refers to a significance level of $10 \%$ or lower. 
Table 7: The Determinants of the Choice of a Specific VC Type:

Pairwise Univariate Probit Regressions

\begin{tabular}{|c|c|c|c|c|c|c|}
\hline \multirow[t]{2}{*}{ Dependent variable } & \multicolumn{2}{|c|}{ Public VC - Bank-dep. VC } & \multicolumn{2}{|c|}{ Public VC - Local ind. VC } & \multicolumn{2}{|c|}{ Public VC - Int. ind. VC } \\
\hline & Coef. & $\mathrm{z}$ & Coef. & $\mathrm{z}$ & Coef. & $\mathrm{z}$ \\
\hline Finished Product & & & .047102 & 0.16 & & \\
\hline Previous Outside Finance & 1.21089 & 2.87 & .8045787 & 1.85 & & \\
\hline Fixed Asset Ratio & & & & & -1.903705 & -1.65 \\
\hline Dummy Repeat E & & & & & -.8791857 & -1.99 \\
\hline Growth Industries & .0457502 & 0.14 & .8951655 & 2.92 & .5313493 & 1.29 \\
\hline Period 1 & -.3960566 & -0.96 & -.2537756 & -0.64 & -1.41504 & -2.76 \\
\hline Period 3 & -.4000993 & -0.96 & -.285756 & -0.82 & -.582316 & -1.08 \\
\hline Constant & .246049 & 0.89 & .0348569 & 0.12 & .6658597 & 1.59 \\
\hline No of Obs. & \multicolumn{2}{|c|}{72} & \multicolumn{2}{|c|}{103} & \multicolumn{2}{|c|}{57} \\
\hline Wald $/ \chi^{2}$ & \multicolumn{2}{|c|}{11.20} & \multicolumn{2}{|c|}{12.61} & \multicolumn{2}{|c|}{13.76} \\
\hline Prob. & \multicolumn{2}{|c|}{0.0245} & \multicolumn{2}{|c|}{0.0273} & \multicolumn{2}{|c|}{0.0172} \\
\hline Pseudo $\mathrm{R}^{2}$ & \multicolumn{2}{|c|}{0.1050} & \multicolumn{2}{|c|}{0.1150} & \multicolumn{2}{|c|}{0.2376} \\
\hline Log Likelihood & \multicolumn{2}{|c|}{-42.146486} & \multicolumn{2}{|c|}{-51.498725} & \multicolumn{2}{|c|}{-30.05986} \\
\hline
\end{tabular}

\begin{tabular}{|c|c|c|c|c|c|c|}
\hline Dependent variable & \multicolumn{2}{|c|}{ Bank-dep. VC - Local ind. VC } & \multicolumn{2}{|c|}{ Bank-dep. VC - Int. ind. VC } & \multicolumn{2}{|c|}{ Local ind. VC - Int. ind. VC } \\
\hline & Coef. & $\mathrm{z}$ & Coef. & $\mathrm{z}$ & Coef. & $\mathrm{z}$ \\
\hline Finished Product & .0076909 & 0.04 & -.335661 & -1.18 & -.2054815 & -0.83 \\
\hline Fixed Asset Ratio & -.2216757 & -0.68 & -1.504153 & -2.75 & -1.224041 & -2.44 \\
\hline Growth Industries & .8253005 & 3.79 & .4717387 & 1.56 & -.4023569 & -1.36 \\
\hline Period 1 & -.3521593 & -1.34 & -1.165536 & -2.73 & -.5834417 & -1.33 \\
\hline Period 3 & .3864149 & 1.48 & -.0361875 & -0.10 & -.3210557 & -1.06 \\
\hline Constant & -.2287669 & -0.92 & -.1085277 & -0.33 & .0132732 & 0.04 \\
\hline No of Obs. & \multicolumn{2}{|c|}{174} & \multicolumn{2}{|c|}{105} & \multicolumn{2}{|c|}{137} \\
\hline Wald $/ \chi^{2}$ & \multicolumn{2}{|c|}{21.89} & \multicolumn{2}{|c|}{22.19} & \multicolumn{2}{|c|}{11.94} \\
\hline Prob. & \multicolumn{2}{|c|}{0.0005} & \multicolumn{2}{|c|}{0.0005} & \multicolumn{2}{|c|}{0.0356} \\
\hline Pseudo $\mathrm{R}^{2}$ & \multicolumn{2}{|c|}{0.1063} & \multicolumn{2}{|c|}{0.1931} & \multicolumn{2}{|c|}{0.0649} \\
\hline Log Likelihood & \multicolumn{2}{|c|}{-105.14277} & \multicolumn{2}{|c|}{-53.352979} & \multicolumn{2}{|c|}{-71.778859} \\
\hline
\end{tabular}

Notes: Probit regression with robust standard errors. Dependent variables are different dummy variables

which allow to compare VC types pairwisely. The respective dependent dummy variable is indicated.

Table 8: The Determinants of the Choice of a Specific VC Type:

Multinomial Probit Regression

\begin{tabular}{|c|c|c|c|}
\hline & $\mathrm{OC}$ & Coef. & $\mathrm{z}$ \\
\hline Outcome Category & 1 & & \\
\hline Finished Product & & -.2451927 & -0.82 \\
\hline Fixed Asset Ratio & & -.9317131 & -1.47 \\
\hline Growth Industries & & -1.020258 & -3.26 \\
\hline Period 1 & & .5357527 & 1.46 \\
\hline Period 3 & & -.1883737 & -0.49 \\
\hline Constant & & .014885 & 0.04 \\
\hline Outcome Category & 2 & & \\
\hline Finished Product & & .0367025 & 0.14 \\
\hline Fixed Asset Ratio & & .2562786 & 0.57 \\
\hline Growth Industries & & -1.036111 & -3.84 \\
\hline Period 1 & & .5075815 & 1.53 \\
\hline Period 3 & & -.4339993 & -1.32 \\
\hline Constant & & .2390522 & 0.79 \\
\hline Outcome Category & 4 & & \\
\hline Finished Product & & -.3029956 & -1.03 \\
\hline Fixed Asset Ratio & & -1.320428 & -2.41 \\
\hline Growth Industries & & -.4526247 & -1.42 \\
\hline Period 1 & & -.680617 & -1.47 \\
\hline Period 3 & & -.4452425 & -1.23 \\
\hline Constant & & .0044159 & 0.01 \\
\hline No of Obs. & & \multicolumn{2}{|c|}{241} \\
\hline Wald $/ \chi^{2}$ & & \multicolumn{2}{|c|}{47.25} \\
\hline Prob. & & \multicolumn{2}{|c|}{0.0000} \\
\hline Log Likelihood & & \multicolumn{2}{|c|}{-282.14457} \\
\hline
\end{tabular}

Notes: Multinomial probit regression with robust standard errors. Dependent variable is the categorial variable VCTYPE which takes value one when a public VC is chosen, value two with a bank-dependent VC, value three with a local independent $\mathrm{VC}$ and value four with an international independent VC. The chosen base category is category 3 . OC refers to the specific outcome categories. 
Table 9: Comparison of the ATT Obtained by Different Matching Methods

\begin{tabular}{|c|c|c|c|c|c|c|}
\hline \multicolumn{7}{|c|}{ Incentive Mechanism Degree } \\
\hline "Control Group vs. Treatment Group & Before Matching (1) & After NN 1 & After GK 1 & "Before Matching (2) & After NN 2 & After GK 2 \\
\hline Public VC vs. Bank-dep. VC & $0.630^{* *}$ & {$\left[0.602^{* * *}\right.$} & {$\left[0.607^{* *}\right]$} & $0.448^{*}$ & 0.401 & $0.417^{* *}$ \\
\hline Bank-dep. VC vs. Public VC & $-0.630 * *$ & $-0.969^{* *}$ & $-0.654 * * *$ & $-0.448^{*}$ & $-0.677^{* *}$ & $-0.413^{*}$ \\
\hline Public VC vs. Local ind. VC & $1.566^{* * *}$ & {$\left[1.523^{* * *}\right]$} & $1.529^{* * *}$ & $1.373^{* * *}$ & {$\left[1.471^{* * *}\right]$} & $1.259^{* * *}$ \\
\hline Local ind. VC vs. Public VC & $-1.566^{* * *}$ & $-1.156^{* * *}$ & $-1.253^{* * *}$ & $-1.373^{* * *}$ & {$[-1.106 * * *]$} & $-0.994^{* * *}$ \\
\hline Public VC vs. Int. ind. VC & $1.563^{* * *}$ & {$[1.734 * * *]$} & $1.672^{* * *}$ & $1.658^{* * *}$ & $1.863^{* * *}$ & $1.649^{* * *}$ \\
\hline Int. ind. VC vs. Public VC & $-1.563^{* * *}$ & $-2.174^{* * *}$ & $-1.910^{* * *}$ & $-1.658^{* * *}$ & $-1.615^{* * *}$ & $-1.689^{* * *}$ \\
\hline Bank-dep. VC vs. Local ind. VC & $0.925^{* * *}$ & $0.583^{* *}$ & $0.673^{* * *}$ & $0.925^{* * *}$ & 0.467 & $0.654^{* *}$ \\
\hline Local ind. VC vs. Bank-dep. VC & $-0.925 * * *$ & $-0.446^{* *}$ & $-0.578^{* * *}$ & $-0.925^{* * *}$ & -0.382 & $-0.565 * * *$ \\
\hline Bank-dep. VC vs. Int. ind. VC & $1.210^{* * *}$ & $0.843^{* *}$ & $1.021 * * *$ & $1.210^{* * *}$ & $0.909^{* *}$ & $0.946^{* * *}$ \\
\hline Int. ind. VC vs. Bank-dep. VC & $-1.210^{* * *}$ & {$\left[-1.603^{* * *}\right]$} & {$\left[-1.269^{* * *}\right]$} & $-1.210^{* * *}$ & {$\left[-1.476^{* * *}\right]$} & {$\left[-1.282^{* * *}\right]$} \\
\hline Local ind. VC vs. Int. ind. VC & 0.284 & 0.298 & 0.220 & 0.284 & 0.028 & 0.207 \\
\hline Int. ind. VC vs. Local ind. VC & -0.284 & {$[-0.322]$} & {$[-0.275]$} & -0.284 & {$[-0.076]$} & {$[-0.183]$} \\
\hline \multicolumn{7}{|c|}{ Voting Rights } \\
\hline Control Group vs. Treatment Group & Before Matching (1) & After NN 1 & After GK 1 & Before Matching (2) & After NN 2 & After GK 2 \\
\hline Public VC vs. Bank-dep. VC & $0.474^{* *}$ & $0.589^{* *}$ & $0.590 * * *$ & 0.272 & 0.160 & 0.219 \\
\hline Bank-dep. VC vs. Public VC & $-0.474^{* *}$ & $-0.769^{* * *}$ & $-0.595^{* * *}$ & -0.272 & -0.420 & $-0.350^{*}$ \\
\hline Public VC vs. Local ind. VC & $1.268^{* * *}$ & $1.206^{* * *}$ & $1.193^{* * *}$ & $1.134^{* * *}$ & {$\left[1.205^{* * *}\right]$} & $1.017^{* * *}$ \\
\hline Local ind. VC vs. Public VC & $-1.268^{* * *}$ & $-1.027 * * *$ & $-1.215^{* * *}$ & $-1.134^{* * *}$ & $-0.935^{* * *}$ & $-0.909^{* * *}$ \\
\hline Public VC vs. Int. ind. VC & $1.348^{* * *}$ & {$\left[1.406^{* * *}\right]$} & $1.500^{* * *}$ & $1.515^{* * *}$ & $1.717^{* * *}$ & $1.426^{* * *}$ \\
\hline Int. ind. VC vs. Public VC & $-1.348^{* * *}$ & $-1.391 * * *$ & $-1.499^{* * *}$ & $-1.515^{* * *}$ & $-1.608^{* * *}$ & $-1.615^{* * *}$ \\
\hline Bank-dep. VC vs. Local ind. VC & $0.861 * * *$ & $0.634^{* * *}$ & $0.619^{* * *}$ & $0.861 * * *$ & $0.498 * * *$ & $0.572^{* * *}$ \\
\hline Local ind. VC vs. Bank-dep. VC & $-0.861 * * *$ & $-0.780 * * *$ & $-0.796^{* * *}$ & $-0.861^{* * *}$ & $-0.747^{* * *}$ & $-0.789^{* *}$ \\
\hline Bank-dep. VC vs. Int. ind. VC & $1.243^{* * *}$ & $0.709 * * *$ & $0.936^{* * *}$ & $1.243^{* * *}$ & $0.783 * * *$ & $0.949 * * *$ \\
\hline Int. ind. VC vs. Bank-dep. VC & $-1.243^{* * *}$ & {$\left[-1.038^{* * *}\right]$} & {$\left[-1.110^{* * *}\right]$} & $-1.243^{* * *}$ & {$\left[-1.028^{* * *}\right]$} & {$\left[-1.142^{* * *}\right]$} \\
\hline Local ind. VC vs. Int. ind. VC & $0.382^{* *}$ & $0.498^{* * *}$ & $0.372 * *$ & $0.382^{* *}$ & $0.516^{* *}$ & $0.369^{* * *}$ \\
\hline Int. ind. VC vs. Local ind. VC & $-0.382^{* *}$ & {$\left[-0.373^{* * *}\right]$} & {$\left[-0.364^{* * *}\right]$} & $-0.382^{* *}$ & {$\left[-0.407^{* * *}\right]$} & {$\left[-0.368^{* * *}\right]$} \\
\hline \multicolumn{7}{|c|}{ Operational Veto Rights } \\
\hline Control Group vs. Treatment Group & Before Matching (1) & After NN 1 & After GK 1 & Before Matching (2) & After NN 2 & After GK 2 \\
\hline Public VC vs. Bank-dep. VC & 0.402 & 0.435 & 0.437 & 0.373 & 0.402 & 0.370 \\
\hline Bank-dep. VC vs. Public VC & -0.402 & -0.701 & -0.390 & -0.373 & -0.598 & -0.355 \\
\hline Public VC vs. Local ind. VC & $0.646^{*}$ & 0.567 & $0.634^{*}$ & $0.779^{* *}$ & {$\left[0.790^{* * *}\right]$} & $0.726^{* * *}$ \\
\hline Local ind. VC vs. Public VC & $-0.646^{*}$ & -0.640 & $-0.844^{* *}$ & $-0.779 * *$ & $-1.113^{* * *}$ & $-0.925^{* * *}$ \\
\hline Public VC vs. Int. ind. VC & $1.309^{* * *}$ & 0.556 & {$[0.971]$} & $1.133^{* * *}$ & {$\left[1.225^{* *}\right.$} & $0.940^{* *}$ \\
\hline Int. ind. VC vs. Public VC & $-1.309^{* * *}$ & {$[-0.550]$} & {$\left[-0.939^{* *}\right]$} & $-1.133^{* * *}$ & $-0.979^{* *}$ & $-1.019^{* * *}$ \\
\hline Bank-dep. VC vs. Local ind. VC & 0.405 & -0.070 & 0.082 & 0.405 & -0.500 & 0.060 \\
\hline Local ind. VC vs. Bank-dep. VC & 0.405 & -0.584 & $-0.581^{*}$ & 0.405 & $-0.687^{*}$ & $-0.592^{*}$ \\
\hline Bank-dep. VC vs. Int. ind. VC & $0.760^{* *}$ & 0.575 & 0.604 & $0.760^{* *}$ & 0.325 & 0.585 \\
\hline Int. ind. VC vs. Bank-dep. VC & $-0.760 * *$ & {$[-0.115]$} & {$[-0.463]$} & $-0.760 * *$ & {$[-0.161]$} & -0.474 \\
\hline Local ind. VC vs. Int. ind. VC & 0.355 & $0.673^{*}$ & 0.414 & 0.355 & 0.539 & 0.423 \\
\hline Int. ind. VC vs. Local ind. VC & 0.355 & {$[-0.268]$} & {$[-0.374]$} & -0.355 & {$[-0.390]$} & {$[-0.400]$} \\
\hline \multicolumn{7}{|c|}{ Structural Veto Rights } \\
\hline Control Group vs. Treatment Group & Before Matching (1) & After NN 1 & After GK 1 & Before Matching (2) & After NN 2 & After GK 2 \\
\hline Public VC vs. Bank-dep. VC & $0.477^{* * *}$ & $0.453^{*}$ & $0.470^{* *}$ & $0.249^{*}$ & 0.113 & 0.217 \\
\hline Bank-dep. VC vs. Public VC & $-0.477^{* * *}$ & $-0.553^{* * *}$ & $-0.445^{* * *}$ & $-0.249^{*}$ & -0.322 & $-0.301 * *$ \\
\hline Public VC vs. Local ind. VC & $0.544^{* * *}$ & $0.444^{* *}$ & $0.458^{* * *}$ & $0.450^{* * *}$ & {$\left[0.397^{* *}\right]$} & $0.343^{* *}$ \\
\hline Local ind. VC vs. Public VC & $-0.544^{* * *}$ & -0.235 & $-0.424^{* * *}$ & $-0.450^{* * *}$ & -0.022 & -0.183 \\
\hline Public VC vs. Int. ind. VC & $0.560^{* * *}$ & $0.604^{*}$ & $0.515^{* * *}$ & $0.645^{* * *}$ & $0.699^{* * *}$ & $0.563^{* * *}$ \\
\hline Int. ind. VC vs. Public VC & $-0.560^{* * *}$ & $-0.571^{* * *}$ & $-0.571^{* * *}$ & $-0.645^{* * *}$ & $-0.643^{* * *}$ & $-0.643^{* * *}$ \\
\hline Bank-dep. VC vs. Local ind. VC & $0.201^{* *}$ & 0.101 & 0.117 & $0.201^{* *}$ & 0.106 & 0.096 \\
\hline Local ind. VC vs. Bank-dep. VC & $-0.201 * *$ & -0.011 & -0.116 & $-0.201^{* *}$ & 0.052 & -0.117 \\
\hline Bank-dep. VC vs. Int. ind. VC & $0.397 * * *$ & 0.194 & $0.269^{* * *}$ & $0.397 * * *$ & 0.200 & $0.272^{* * *}$ \\
\hline Int. ind. VC vs. Bank-dep. VC & $-0.397^{* * *}$ & {$\left[-0.378^{* * *}\right]$} & {$\left[-0.378^{* * *}\right]$} & $-0.397^{* * *}$ & {$[-0.391 * * *]$} & {$\left[-0.391^{* * *}\right]$} \\
\hline Local ind. VC vs. Int. ind. VC & $0.196^{*}$ & $0.371^{* *}$ & $0.209^{* *}$ & $0.196^{*}$ & $0.371^{* *}$ & $0.209^{* * *}$ \\
\hline Int. ind. $\mathrm{VC}$ vs. Local ind. VC & $-0.196 *$ & {$\left[-0.211^{* * *}\right]$} & {$\left[-0.211^{* * *}\right]$} & $-0.196^{*}$ & {$[-0.192 * *]$} & {$\left[-0.192^{* * *}\right]$} \\
\hline \multicolumn{7}{|c|}{ Liquidation Rights } \\
\hline Control Group vs. Treatment Group & Before Matching (1) & After NN 1 & After GK 1 & $\overline{\text { Before Matching (2) }}$ & After NN 2 & After GK 2 \\
\hline Public VC vs. Bank-dep. VC & -0.119 & {$[-0.086]$} & {$[-0.065]$} & -0.060 & 0.051 & -0.008 \\
\hline Bank-dep. VC vs. Public VC & 0.119 & {$[0.036]$} & 0.069 & 0.060 & -0.024 & 0.053 \\
\hline Public VC vs. Local ind. VC & 0.050 & -0.015 & -0.008 & 0.062 & {$[0.021]$} & 0.001 \\
\hline Local ind. VC vs. Public VC & -0.050 & -0.060 & -0.067 & -0.062 & -0.097 & -0.063 \\
\hline Public VC vs. Int. ind. VC & 0.077 & 0.050 & 0.027 & $0.120^{*}$ & 0.073 & 0.045 \\
\hline Int. ind. VC vs. Public VC & -0.077 & -0.087 & {$[-0.094]$} & $-0.120^{*}$ & -0.133 & -0.060 \\
\hline Bank-dep. VC vs. Local ind. VC & $0.122^{* *}$ & 0.064 & 0.096 & $0.122^{* *}$ & 0.084 & 0.097 \\
\hline Local ind. VC vs. Bank-dep. VC & $-0.122^{* *}$ & {$[-0.154]$} & -0.092 & $-0.122^{* *}$ & $-0.136^{*}$ & -0.091 \\
\hline Bank-dep. VC vs. Int. ind. VC & $0.180^{* *}$ & 0.137 & $0.172^{* *}$ & $0.180^{* *}$ & 0.141 & $0.171^{* *}$ \\
\hline Int. ind. $\mathrm{VC}$ vs. Bank-dep. VC & $-0.180^{* *}$ & -0.137 & {$[-0.118]$} & $-0.180^{* *}$ & {$[-0.135]$} & {$[-0.116]$} \\
\hline Local ind. VC vs. Int. ind. VC & 0.058 & 0.036 & 0.055 & 0.058 & 0.130 & 0.054 \\
\hline Int. ind. VC vs. Local ind. VC & -0.058 & {$[0.012]$} & {$[-0.027]$} & -0.058 & {$[0.000]$} & {$[-0.046]$} \\
\hline
\end{tabular}

Notes: NN relates to tied nearest neighbor and GK to Gaussian kernel matching. The numbers refer to the two different specifications in order to compute the propensity scores: $1=$ propensity score based on pairwise univariate probit models; $2=$ propensity scores based on multinomial probit models. The bandwidth of the Gaussian is chosen by the rule of thumb of Silverman (1986) which is given by $h=0,9 A n^{-\frac{1}{5}}$ whereby $\mathrm{A}=$ min [standard deviation; interquartile range/1.34] and $\mathrm{n}$ the number of observations for the respective subsamples. ${ }^{* * *},{ }^{* * *}$ refer to a significance level of $10 \%, 5 \%$ and $1 \%$ respectively. Standard errors are obtained by bootstrapping with 50 repetitions. Indications in parenthesis [] signal that the balancing property is not fulfilled, i.e. at least the mean of one covariate differs at the $10 \%$ level between treated and controls. 
Table 10: Indicators of Matching Quality 1 (Propensity Scores of the Pairwise Probit Models)

\begin{tabular}{|c|c|c|c|c|c|c|c|c|c|}
\hline & $\begin{array}{c}\text { Treatment } \\
\text { (No. of obs.) }\end{array}$ & $\begin{array}{l}\text { Comparison } \\
\text { (No. of obs.) }\end{array}$ & $\begin{array}{c}\text { Probit-ps- } R^{2} \\
\text { before }\end{array}$ & $\begin{array}{c}\text { Probit-ps- } R^{2} \\
\text { after }\end{array}$ & $\begin{array}{c}\operatorname{Pr}>\chi^{2} \\
\text { before }\end{array}$ & $\begin{array}{c}\operatorname{Pr}>\chi^{2} \\
\text { after }\end{array}$ & $\begin{array}{c}\text { Med. (max.) } \\
\text { bias } \\
\text { before } \\
\end{array}$ & $\begin{array}{c}\text { Med. (max.) } \\
\text { bias } \\
\text { after } \\
\end{array}$ & $\begin{array}{c}\% \text { loss due } \\
\text { due to } \\
\text { CS } \\
\end{array}$ \\
\hline \multicolumn{10}{|c|}{ Incentive mechanism degree } \\
\hline $\mathrm{NN}$ & Bank-dep. VC & Public VC & 0.105 & 0.057 & 0.042 & 0.227 & $14.0(74.1)$ & $3.5(7.0)$ & 15.28 \\
\hline GK & $(46)$ & $(26)$ & & 0.055 & & 0.250 & & $0.3(4.8)$ & \\
\hline $\mathrm{NN}$ & Public VC & Bank-dep. VC & & -0.000 & & 1.000 & & $0.0(0.0)$ & 0.00 \\
\hline GK & $(26)$ & $(46)$ & & 0.003 & & 0.987 & & $5.7(8.2)$ & \\
\hline $\mathrm{NN}$ & Local ind. VC & Public VC & 0.114 & 0.017 & 0.022 & 0.783 & $21.9(69.6)$ & $3.3(4.1)$ & 7.84 \\
\hline GK & $(76)$ & $(26)$ & & 0.017 & & 0.789 & & $4.7(11.9)$ & \\
\hline $\mathrm{NN}$ & Public VC & Local ind. VC & & 0.003 & & 0.996 & & $7.8(9.8)$ & 0.00 \\
\hline GK & $(26)$ & $(76)$ & & 0.002 & & 0.997 & & $4.2(10.3)$ & \\
\hline $\mathrm{NN}$ & Int. ind. $\mathrm{VC}$ & Public VC & 0.238 & 0.100 & 0.002 & 0.340 & $52.4(69.4)$ & $13.3(46.6)$ & 24.56 \\
\hline GK & $(30)$ & $(27)$ & & 0.113 & & 0.138 & & $13.8(19.9)$ & \\
\hline $\mathrm{NN}$ & Public VC & Int. ind. $\mathrm{VC}$ & & 0.070 & & 0.599 & & $25.2(43.3)$ & 7.02 \\
\hline GK & $(27)$ & $(30)$ & & 0.048 & & 0.579 & & $7.5(26.4)$ & \\
\hline $\mathrm{NN}$ & Local ind. VC & Bank-dep. VC & 0.105 & 0.005 & 0.000 & 0.955 & $29.3(68.1)$ & $2.5(8.5)$ & 1.73 \\
\hline GK & $(102)$ & $(71)$ & & 0.005 & & 0.939 & & $5.5(17.1)$ & \\
\hline $\mathrm{NN}$ & Bank-dep. VC & Local ind. VC & & 0.001 & & 0.998 & & $3.4(6.6)$ & 0.00 \\
\hline GK & $(71)$ & $(102)$ & & 0.002 & & 0.993 & & $4.2(9.6)$ & \\
\hline $\mathrm{NN}$ & Int. ind. VC & Bank-dep. VC & 0.193 & 0.009 & 0.000 & 0.980 & $63.0(66.2)$ & $6.2(8.0)$ & 0.00 \\
\hline GK & $(34)$ & $(71)$ & & 0.002 & & 0.997 & & $4.4(6.7)$ & \\
\hline $\mathrm{NN}$ & Bank-dep. VC & Int. ind. VC & & 0.106 & & 0.014 & & $20.9(35.7)$ & 19.05 \\
\hline GK & $(71)$ & $(34)$ & & 0.062 & & 0.117 & & $6.6(11.4)$ & \\
\hline $\mathrm{NN}$ & Int. ind. $\mathrm{VC}$ & Local ind. VC & 0.067 & 0.037 & 0.068 & 0.506 & $27.6(49.7)$ & $11.8(20.0)$ & 0.00 \\
\hline GK & $(34)$ & (102) & & 0.003 & & 0.988 & & $3.6(7.6)$ & \\
\hline $\mathrm{NN}$ & Local ind. VC & Int. ind. VC & & 0.035 & & 0.278 & & $5.6(11.8)$ & 12.50 \\
\hline GK & $(102)$ & $(34)$ & & 0.040 & & 0.183 & & $3.3(8.6)$ & \\
\hline \multicolumn{10}{|c|}{ Voting rights } \\
\hline $\mathrm{NN}$ & Bank-dep. VC & Public VC & 0.086 & 0.040 & 0.101 & 0.444 & $9.7(66.0)$ & $3.6(7.1)$ & 11.76 \\
\hline GK & $(42)$ & $(26)$ & & 0.038 & & 0.476 & & $4.0(7.4)$ & \\
\hline $\mathrm{NN}$ & Public VC & Bank-dep. VC & & -0.000 & & 1.000 & & $0.0(0.0)$ & 0.00 \\
\hline GK & (26) & $(42)$ & & 0.004 & & 0.987 & & $6.3(8.5)$ & \\
\hline $\mathrm{NN}$ & Local ind. VC & Public VC & 0.114 & 0.017 & 0.022 & 0.783 & $21.9(69.6)$ & $3.3(4.1)$ & 7.84 \\
\hline GK & $(76)$ & (26) & & 0.017 & & 0.789 & & $4.7(11.9)$ & \\
\hline $\mathrm{NN}$ & Public VC & Local ind. VC & & 0.003 & & 0.996 & & $7.8(9.8)$ & 0.00 \\
\hline GK & $(26)$ & $(76)$ & & 0.002 & & 0.997 & & $4.2(10.3)$ & \\
\hline $\mathrm{NN}$ & Int. ind. $\mathrm{VC}$ & Public VC & 0.238 & 0.100 & 0.002 & 0.340 & $52.4(69.4)$ & $13.3(46.6)$ & 24.56 \\
\hline GK & (30) & $(27)$ & & 0.113 & & 0.138 & & $13.8(23.1)$ & \\
\hline $\mathrm{NN}$ & Public VC & Int. ind. $\mathrm{VC}$ & & 0.070 & & 0.599 & & $25.2(43.3)$ & 7.02 \\
\hline GK & (27) & $(30)$ & & 0.048 & & 0.579 & & $7.5(26.4)$ & \\
\hline $\mathrm{NN}$ & Local ind. VC & Bank-dep. VC & 0.093 & 0.005 & 0.001 & 0.966 & $25.1(64.2)$ & $2.5(8.5)$ & 1.79 \\
\hline GK & $(101)$ & $(67)$ & & 0.004 & & 0.963 & & $4.2(15.5)$ & \\
\hline $\mathrm{NN}$ & Bank-dep. VC & Local ind. VC & & 0.002 & & 0.998 & & $3.6(7.0)$ & 0.00 \\
\hline GK & (67) & $(101)$ & & 0.002 & & 0.996 & & $2.8(9.2)$ & \\
\hline $\mathrm{NN}$ & Int. ind. VC & Bank-dep. VC & 0.174 & 0.010 & 0.001 & 0.975 & $55.4(64.6)$ & $6.1(9.4)$ & 0.00 \\
\hline GK & $(33)$ & (67) & & 0.002 & & 0.997 & & $3.9(6.1)$ & \\
\hline $\mathrm{NN}$ & Bank-dep. VC & Int. ind. VC & & 0.104 & & 0.021 & & $21.3(37.0)$ & 18.00 \\
\hline GK & $(67)$ & $(33)$ & & 0.061 & & 0.143 & & $5.5(14.8)$ & \\
\hline $\mathrm{NN}$ & Int. ind. VC & Local ind. VC & 0.064 & 0.038 & 0.087 & 0.496 & $24.2(48.5)$ & $12.1(20.7)$ & 0.00 \\
\hline GK & (33) & (101) & & 0.003 & & 0.989 & & $3.1(9.8)$ & \\
\hline $\mathrm{NN}$ & Local ind. VC & Int. ind. VC & & 0.036 & & 0.268 & & $5.4(11.7)$ & 12.69 \\
\hline GK & $(101)$ & $(33)$ & & 0.041 & & 0.182 & & $3.9(8.0)$ & \\
\hline \multicolumn{10}{|c|}{ Operational Veto rights } \\
\hline $\mathrm{NN}$ & Bank-dep. VC & Public VC & 0.057 & 0.041 & 0.353 & 0.517 & $16.8(50.2)$ & $4.5(9.2)$ & 10.53 \\
\hline GK & $(33)$ & $(24)$ & & 0.041 & & 0.526 & & $3.4(5.3)$ & \\
\hline $\mathrm{NN}$ & Public VC & Bank-dep. VC & & 0.000 & & 1.000 & & $0.0(0.0)$ & 0.00 \\
\hline GK & $(24)$ & $(33)$ & & 0.005 & & 0.980 & & $3.4(16.2)$ & \\
\hline $\mathrm{NN}$ & Local ind. VC & Public VC & 0.096 & 0.034 & 0.117 & 0.647 & $16.2(65.1)$ & $0.0(6.8)$ & 8.33 \\
\hline GK & $(48)$ & $(24)$ & & 0.022 & & 0.828 & & $4.4(9.1)$ & \\
\hline $\mathrm{NN}$ & Public VC & Local ind. VC & & 0.010 & & 0.975 & & $9.5(11.8)$ & 0.00 \\
\hline GK & $(24)$ & $(48)$ & & 0.005 & & 0.991 & & $8.2(9.0)$ & \\
\hline $\mathrm{NN}$ & Int. ind. $\mathrm{VC}$ & Public VC & 0.475 & 0.177 & 0.000 & 0.361 & $55.3(72.0)$ & $0.00(23.4)$ & 19.51 \\
\hline GK & $(17)$ & $(24)$ & & 0.298 & & 0.008 & & $30.1(46.7)$ & \\
\hline $\mathrm{NN}$ & Public VC & Int. ind. VC & & 0.318 & & 0.032 & & $76.7(91.8)$ & 9.76 \\
\hline GK & $(24)$ & $(17)$ & & 0.278 & & 0.008 & & $44.9(73.1)$ & \\
\hline
\end{tabular}




\begin{tabular}{|c|c|c|c|c|c|c|c|c|c|}
\hline & $\begin{array}{c}\text { Treatment } \\
\text { (No. of obs.) }\end{array}$ & $\begin{array}{l}\text { Comparison } \\
\text { (No. of obs.) }\end{array}$ & $\begin{array}{c}\text { Probit-ps- } R^{2} \\
\text { before }\end{array}$ & $\begin{array}{c}\text { Probit-ps- } R^{2} \\
\text { after }\end{array}$ & $\begin{array}{c}\operatorname{Pr}>\chi^{2} \\
\text { before }\end{array}$ & $\begin{array}{c}\operatorname{Pr}>\chi^{2} \\
\text { after }\end{array}$ & $\begin{array}{c}\text { Med. (max.) } \\
\text { bias } \\
\text { before } \\
\end{array}$ & $\begin{array}{c}\text { Med. (max.) } \\
\text { bias } \\
\text { after } \\
\end{array}$ & $\begin{array}{c}\% \text { loss due } \\
\text { due to } \\
\text { CS } \\
\end{array}$ \\
\hline \multicolumn{10}{|c|}{ Operational Veto rights (cont.) } \\
\hline NN & Local ind. VC & Bank-dep. VC & 0.083 & 0.014 & 0.021 & 0.863 & $9.6(66.5)$ & $4.2(6.4)$ & 3.45 \\
\hline GK & $(66)$ & $(50)$ & & 0.004 & & 0.983 & & $3.3(5.6)$ & \\
\hline NN & Bank-dep. VC & Local ind. VC & & 0.021 & & 0.767 & & $4.8(31.7)$ & 0.00 \\
\hline GK & $(50)$ & $(66)$ & & 0.006 & & 0.967 & & $9.6(11.0)$ & \\
\hline $\mathrm{NN}$ & Int. ind. $\mathrm{VC}$ & Bank-dep. VC & 0.208 & 0.018 & 0.004 & 0.967 & $52.6(64.3)$ & $10.5(27.1)$ & 0.00 \\
\hline GK & $(20)$ & $(50)$ & & 0.021 & & 0.849 & & $8.6(23.9)$ & \\
\hline NN & Bank-dep. VC & Int. ind. VC & & 0.166 & & 0.012 & & $35.0(54.3)$ & 14.29 \\
\hline GK & $(50)$ & $(20)$ & & 0.084 & & 0.153 & & $17.9(35.9)$ & \\
\hline NN & Int. ind. $\mathrm{VC}$ & Local ind. VC & 0.102 & 0.017 & 0.089 & 0.937 & $37.7(54.7)$ & $10.4(11.8)$ & 0.00 \\
\hline GK & $(20)$ & $(66)$ & & 0.017 & & 0.852 & & $8.3(15.7$ & \\
\hline NN & Local ind. VC & Int. ind. VC & & 0.117 & & 0.021 & & $5.1(19.1)$ & 29.07 \\
\hline GK & $(66)$ & $(20)$ & & 0.108 & & 0.030 & & $7.1(12.2)$ & \\
\hline \multicolumn{10}{|c|}{ Structural Veto rights } \\
\hline $\mathrm{NN}$ & Bank-dep. VC & Public VC & 0.068 & 0.041 & 0.222 & 0.472 & $15.6(56.9)$ & $3.9(8.2)$ & 11.29 \\
\hline GK & $(37)$ & $(25)$ & & 0.041 & & 0.484 & & $5.9(7.8)$ & \\
\hline $\mathrm{NN}$ & Public VC & Bank-dep. VC & & 0.000 & & 1.000 & & $0.0(0.0)$ & 0.00 \\
\hline GK & $(25)$ & $(37)$ & & 0.003 & & 0.995 & & $2.8(8.8)$ & \\
\hline $\mathrm{NN}$ & Local ind. VC & Public VC & 0.094 & 0.022 & 0.072 & 0.724 & $19.3(59.4)$ & $3.8(4.6)$ & 8.60 \\
\hline GK & $(68)$ & $(25)$ & & 0.023 & & 0.714 & & $7.0(11.4)$ & \\
\hline $\mathrm{NN}$ & Public VC & Local ind. VC & & 0.003 & & 0.997 & & $8.2(9.9)$ & 0.00 \\
\hline GK & $(25)$ & $(68)$ & & 0.001 & & 0.999 & & $1.7(9.0)$ & \\
\hline $\mathrm{NN}$ & Int. ind. VC & Public VC & 0.215 & 0.087 & 0.008 & 0.459 & $40.0(73.4)$ & $13.1(45.3)$ & 22.64 \\
\hline GK & $(28)$ & $(25)$ & & 0.099 & & 0.229 & & $17.4(24.9)$ & \\
\hline NN & Public VC & Int. ind. VC & & 0.075 & & 0.592 & & $19.1(46.1)$ & 7.55 \\
\hline GK & $(25)$ & $(28)$ & & 0.048 & & 0.621 & & $7.4(19.0)$ & \\
\hline $\mathrm{NN}$ & Local ind. VC & Bank-dep. VC & 0.064 & 0.010 & 0.025 & 0.872 & $17.0(54.1)$ & $2.7(15.7)$ & 2.00 \\
\hline GK & $(92)$ & $(58)$ & & 0.003 & & 0.990 & & $3.7(11.1)$ & \\
\hline NN & Bank-dep. VC & Local ind. VC & & 0.003 & & 0.992 & & $4.2(10.3)$ & 0.00 \\
\hline GK & $(58)$ & $(92)$ & & 0.001 & & 0.999 & & $1.1(6.9)$ & \\
\hline $\mathrm{NN}$ & Int. ind. VC & Bank-dep. VC & 0.148 & 0.015 & 0.005 & 0.945 & $47.0(58.0)$ & $8.1(12.9)$ & 0.00 \\
\hline GK & $(31)$ & $(58)$ & & 0.002 & & 0.998 & & $4.4(6.5)$ & \\
\hline $\mathrm{NN}$ & Bank-dep. VC & Int. ind. VC & & 0.097 & & 0.050 & & $27.6(35.7)$ & 14.61 \\
\hline GK & $(58)$ & $(31)$ & & 0.046 & & 0.346 & & $8.2(14.1)$ & \\
\hline $\mathrm{NN}$ & Int. ind. VC & Local ind. VC & 0.064 & 0.015 & 0.116 & 0.900 & $22.6(49.4)$ & $10.3(14.3)$ & 0.00 \\
\hline GK & $(31)$ & $(92)$ & & 0.002 & & 0.997 & & $1.9(8.4)$ & \\
\hline NN & Local ind. VC & Int. ind. VC & & 0.041 & & 0.246 & & $2.5(13.2)$ & 13.01 \\
\hline GK & $(92)$ & $(31)$ & & 0.042 & & 0.212 & & $4.6(6.0)$ & \\
\hline \multicolumn{10}{|c|}{ Liquidation rights } \\
\hline $\mathrm{NN}$ & Bank-dep. VC & Public VC & 0.105 & 0.057 & 0.042 & 0.227 & $14.0(74.1)$ & $3.5(7.0)$ & 15.28 \\
\hline GK & $(46)$ & (26) & & 0.055 & & 0.250 & & $0.3(4.8)$ & \\
\hline $\mathrm{NN}$ & Public VC & Bank-dep. VC & & -0.000 & & 1.000 & & $0.0(0.0)$ & 0.00 \\
\hline GK & $(26)$ & $(46)$ & & 0.003 & & 0.987 & & $5.7(8.2)$ & \\
\hline NN & Local ind. VC & Public VC & 0.110 & 0.014 & 0.027 & 0.849 & $21.3(68.9)$ & $3.3(4.1)$ & 6.93 \\
\hline GK & $(75)$ & (26) & & 0.014 & & 0.852 & & $4.8(11.9)$ & \\
\hline $\mathrm{NN}$ & Public VC & Local ind. VC & & 0.003 & & 0.996 & & $7.9(9.7)$ & 0.00 \\
\hline GK & $(26)$ & $(75)$ & & 0.002 & & 0.997 & & $4.4(10.2)$ & \\
\hline $\mathrm{NN}$ & Int. ind. VC & Public VC & 0.272 & 0.093 & 0.001 & 0.398 & $54.7(68.6)$ & $17.3(34.3)$ & 25.00 \\
\hline GK & (29) & (27) & & 0.134 & & 0.086 & & $15.1(32.7)$ & \\
\hline NN & Public VC & Int. ind. VC & & 0.070 & & 0.599 & & $26.4(44.7)$ & 7.14 \\
\hline GK & $(27)$ & $(29)$ & & 0.074 & & 0.338 & & $14.6(45.5)$ & \\
\hline $\mathrm{NN}$ & Local ind. VC & Bank-dep. VC & 0.104 & 0.005 & 0.000 & 0.966 & $29.9(67.5)$ & $2.5(8.8)$ & 1.74 \\
\hline GK & $(101)$ & $(71)$ & & 0.005 & & 0.937 & & $5.2(17.4)$ & \\
\hline NN & Bank-dep. VC & Local ind. VC & & 0.001 & & 0.998 & & $3.4(6.6)$ & 0.00 \\
\hline GK & $(71)$ & $(101)$ & & 0.002 & & 0.992 & & $4.7(9.5)$ & \\
\hline $\mathrm{NN}$ & Int. ind. VC & Bank-dep. VC & 0.207 & 0.009 & 0.000 & 0.979 & $63.3(70.0)$ & $6.6(8.5)$ & 0.00 \\
\hline GK & $(32)$ & $(71)$ & & 0.004 & & 0.990 & & $4.9(9.6)$ & \\
\hline NN & Bank-dep. VC & Int. ind. VC & & 0.100 & & 0.022 & & $25.0(32.1)$ & 19.42 \\
\hline GK & $(71)$ & $(32)$ & & 0.061 & & 0.129 & & $7.6(16.1)$ & \\
\hline $\mathrm{NN}$ & Int. ind. VC & Local ind. VC & 0.075 & 0.025 & 0.052 & 0.717 & $28.0(54.8)$ & $12.6(14.3)$ & 0.00 \\
\hline GK & $(32)$ & $(101)$ & & 0.005 & & 0.972 & & $3.6(13.3)$ & \\
\hline $\mathrm{NN}$ & Local ind. VC & Int. ind. VC & & 0.039 & & 0.225 & & $8.7(15.5)$ & 12.78 \\
\hline GK & $(101)$ & $(32)$ & & 0.044 & & 0.151 & & $3.3(12.0)$ & \\
\hline
\end{tabular}

Notes: The number of observations refers to the number of the complete subsample (out of common support area included). Different measures of the balancing of the variables are indicated for the two matching methods. NN refers to tied nearest neighbor matching; GK refers to Gaussian kernel matching. Pseudo- $R^{2}$ results from a probit model with the pairwise VC dummies as endogenous variables and the respective $\mathrm{X}$ variables as exogenous variables. This measure is indicated for the unmatched as well as the matched sample. $\mathrm{Pr}>\chi^{2}$ indicates the p-value of the likelihood-ratio test before and after matching testing the null hypothesis of joint insignificance of all the covariates. The standardized bias following Rosenbaum and Rubin (1983) is calculated for every covariate. The bias is the difference in the means of the respective covariate in the unmatched and matched subsamples as a percentage of the square root of the average of the sample variances in the full subsample. The median of the standardized bias as well as the maximum values are indicated for the unmatched and the matched subsamples. The last column indicates the percentage of observations which are lost due to the common support assumption. 
Table 11: Indicators of Matching Quality 2 (P. Scores of the Multinomial Probit Model)

\begin{tabular}{|c|c|c|c|c|c|c|c|c|c|}
\hline & $\begin{array}{c}\text { Treatment } \\
\text { (No. of obs.) }\end{array}$ & $\begin{array}{l}\text { Comparison } \\
\text { (No. of obs.) }\end{array}$ & $\begin{array}{c}\text { Probit-ps- } R^{2} \\
\text { before }\end{array}$ & $\begin{array}{c}\text { Probit-ps- } R^{2} \\
\text { after }\end{array}$ & $\begin{array}{c}\operatorname{Pr}>\chi^{2} \\
\text { before }\end{array}$ & $\begin{array}{c}\operatorname{Pr}>\chi^{2} \\
\text { after }\end{array}$ & $\begin{array}{c}\text { Med. (max.) } \\
\text { bias } \\
\text { before }\end{array}$ & $\begin{array}{c}\text { Med. (max.) } \\
\text { bias } \\
\text { after }\end{array}$ & $\begin{array}{c}\% \text { loss due } \\
\text { due to } \\
\text { CS }\end{array}$ \\
\hline \multicolumn{10}{|c|}{ Incentive mechanism degree } \\
\hline $\mathrm{NN}$ & Bank-dep. VC & Public VC & \multirow[t]{4}{*}{0.044} & 0.015 & \multirow[t]{4}{*}{0.333} & 0.835 & \multirow[t]{4}{*}{$9.6(42.6)$} & $3.1(15.3)$ & \multirow[t]{4}{*}{5.77} \\
\hline GK & $(71)$ & $(33)$ & & 0.020 & & 0.717 & & $9.2(14.7)$ & \\
\hline $\mathrm{NN}$ & Public VC & Bank-dep. VC & & 0.014 & & 0.942 & & $6.3(20.2)$ & \\
\hline GK & (33) & $(71)$ & & 0.003 & & 0.993 & & $2.2(10.0)$ & \\
\hline $\mathrm{NN}$ & Local ind. VC & Public VC & \multirow[t]{4}{*}{0.102} & 0.041 & \multirow[t]{4}{*}{0.009} & 0.199 & \multirow[t]{4}{*}{$22.2(57.3)$} & $10.1(23.3)$ & \multirow[t]{4}{*}{5.19} \\
\hline GK & $(102)$ & (33) & & 0.013 & & 0.795 & & $3.1(9.9)$ & \\
\hline $\mathrm{NN}$ & Public VC & Local ind. VC & & 0.020 & & 0.802 & & $6.4(21.9)$ & \\
\hline GK & $(33)$ & $(102)$ & & 0.001 & & 1.000 & & $2.5(3.7)$ & \\
\hline $\mathrm{NN}$ & Int. ind. $\mathrm{VC}$ & Public VC & \multirow[t]{4}{*}{0.133} & 0.038 & \multirow[t]{4}{*}{0.030} & 0.704 & \multirow[t]{4}{*}{$29.6(65.9)$} & $15.1(23.6)$ & 0.00 \\
\hline GK & $(34)$ & (33) & & 0.011 & & 0.959 & & $7.3(19.8)$ & \\
\hline $\mathrm{NN}$ & Public VC & Int. ind. VC & & 0.026 & & 0.856 & & $5.8(33.5)$ & 4.48 \\
\hline GK & (33) & $(34)$ & & 0.026 & & 0.783 & & $9.5(20.9)$ & \\
\hline $\mathrm{NN}$ & Local ind. VC & Bank-dep. VC & 0.105 & 0.007 & 0.000 & 0.920 & $29.3(68.1)$ & $2.3(8.4)$ & 5.78 \\
\hline GK & $(102)$ & $(71)$ & & 0.010 & & 0.810 & & $3.4(11.3)$ & \\
\hline $\mathrm{NN}$ & Bank-dep. VC & Local ind. VC & & 0.006 & & 0.955 & & $6.0(14.1)$ & 0.00 \\
\hline GK & $(71)$ & $(102)$ & & 0.001 & & 0.997 & & $2.6(7.3)$ & \\
\hline $\mathrm{NN}$ & Int. ind. VC & Bank-dep. VC & 0.193 & 0.008 & 0.000 & 0.983 & $63.0(66.2)$ & $6.7(16.1)$ & 0.95 \\
\hline GK & $(34)$ & $(71)$ & & 0.003 & & 0.994 & & $4.7(10.6)$ & \\
\hline $\mathrm{NN}$ & Bank-dep. VC & Int. ind. $\mathrm{VC}$ & & 0.125 & & 0.006 & & $21.0(44.6)$ & 18.10 \\
\hline GK & $(71)$ & $(34)$ & & 0.060 & & 0.128 & & $5.7(16.1)$ & \\
\hline $\mathrm{NN}$ & Int. ind. VC & Local ind. VC & 0.067 & 0.005 & 0.068 & 0.989 & $27.6(49.7)$ & $6.7(9.7)$ & 0.00 \\
\hline GK & $(34)$ & $(102)$ & & 0.004 & & 0.978 & & $3.7(10.7)$ & \\
\hline $\mathrm{NN}$ & Local ind. VC & Int. ind. VC & & 0.060 & & 0.052 & & $2.9(24.9)$ & 14.71 \\
\hline GK & $(102)$ & (34) & & 0.050 & & 0.098 & & $5.7(7.9)$ & \\
\hline & & & & Voting 1 & & & & & \\
\hline $\mathrm{NN}$ & Bank-dep. VC & Public VC & 0.039 & 0.017 & 0.423 & 0.815 & $4.6(39.3)$ & $3.5(16.0)$ & 5.00 \\
\hline GK & (67) & $(33)$ & & 0.018 & & 0.777 & & $10.4(11.2)$ & \\
\hline $\mathrm{NN}$ & Public VC & Bank-dep. VC & & 0.014 & & 0.942 & & $6.3(20.2)$ & 1.00 \\
\hline GK & (33) & $(67)$ & & 0.004 & & 0.989 & & $3.4(13.5)$ & \\
\hline $\mathrm{NN}$ & Local ind. VC & Public VC & 0.104 & 0.044 & 0.008 & 0.168 & $42.4(59.1)$ & $10.2(24.3)$ & 5.22 \\
\hline GK & $(101)$ & (33) & & 0.014 & & 0.764 & & $4.3(12.4)$ & \\
\hline $\mathrm{NN}$ & Public VC & Local ind. VC & & 0.020 & & 0.802 & & $6.5(21.9)$ & 0.00 \\
\hline GK & (33) & $(101)$ & & 0.001 & & 1.000 & & $2.7(3.1)$ & \\
\hline $\mathrm{NN}$ & Int. ind. VC & Public VC & 0.127 & 0.040 & 0.041 & 0.696 & $28.0(65.2)$ & $15.5(24.3)$ & 0.00 \\
\hline GK & $(33)$ & (33) & & 0.010 & & 0.970 & & $5.4(18.4)$ & \\
\hline $\mathrm{NN}$ & Public VC & Int. ind. VC & & 0.026 & & 0.861 & & $5.8(33.4)$ & 9.09 \\
\hline GK & (33) & $(33)$ & & 0.026 & & 0.795 & & $9.7(20.8)$ & \\
\hline $\mathrm{NN}$ & Local ind. VC & Bank-dep. VC & 0.093 & 0.007 & 0.001 & 0.921 & $25.1(64.2)$ & $2.4(8.4)$ & 5.95 \\
\hline GK & $(101)$ & (67) & & 0.008 & & 0.857 & & $1.9(10.5)$ & \\
\hline $\mathrm{NN}$ & Bank-dep. VC & Local ind. VC & & 0.007 & & 0.939 & & $6.4(15.3)$ & 0.00 \\
\hline GK & $(67)$ & (101) & & 0.001 & & 0.999 & & $3.7(5.0)$ & \\
\hline $\mathrm{NN}$ & Int. ind. VC & Bank-dep. VC & 0.174 & 0.016 & 0.001 & 0.930 & $55.4(64.6)$ & $10.3(19.6)$ & 1.00 \\
\hline GK & (33) & $(67)$ & & 0.003 & & 0.993 & & $4.2(10.8)$ & \\
\hline $\mathrm{NN}$ & Bank-dep. VC & Int. ind. VC & & 0.124 & & 0.009 & & $21.7(46.0)$ & 17.00 \\
\hline GK & $(67)$ & $(33)$ & & 0.059 & & 0.156 & & $7.9(18.1)$ & \\
\hline $\mathrm{NN}$ & Int. ind. VC & Local ind. VC & 0.064 & 0.005 & 0.087 & 0.988 & $24.2(48.5)$ & $6.9(9.9)$ & 0.00 \\
\hline GK & (33) & $(101)$ & & 0.005 & & 0.972 & & $3.6(13.4)$ & \\
\hline $\mathrm{NN}$ & Local ind. VC & Int. ind. $\mathrm{VC}$ & & 0.064 & & 0.040 & & $4.9(28.0)$ & 14.93 \\
\hline GK & $(101)$ & $(33)$ & & 0.051 & & 0.094 & & $4.5(11.0)$ & \\
\hline & & & & Operational & to rights & & & & \\
\hline $\mathrm{NN}$ & Bank-dep. VC & Public VC & 0.028 & 0.062 & 0.701 & 0.267 & $10.3(36.1)$ & $8.9(34.4)$ & 5.00 \\
\hline GK & (50) & (30) & & 0.039 & & 0.505 & & $7.6(21.9)$ & \\
\hline $\mathrm{NN}$ & Public VC & Bank-dep. VC & & 0.022 & & 0.885 & & $0.8(27.2)$ & 1.25 \\
\hline GK & $(30)$ & $(50)$ & & 0.009 & & 0.964 & & $5.7(11.9)$ & \\
\hline $\mathrm{NN}$ & Local ind. VC & Public VC & 0.114 & 0.079 & 0.018 & 0.074 & $31.4(59.0)$ & $15.2(35.9)$ & 4.17 \\
\hline GK & $(66)$ & (30) & & 0.040 & & 0.380 & & $8.9(34.3)$ & \\
\hline $\mathrm{NN}$ & Public VC & Local ind. VC & & 0.015 & & 0.925 & & $7.3(16.5)$ & 0.00 \\
\hline GK & $(30)$ & $(66)$ & & 0.016 & & 0.833 & & $11.8(14.6)$ & \\
\hline $\mathrm{NN}$ & Int. ind. VC & Public VC & 0.182 & 0.096 & 0.032 & 0.429 & $38.6(68.4)$ & $12.9(44.8)$ & 0.00 \\
\hline GK & $(20)$ & (30) & & 0.049 & & 0.634 & & $4.0(36.7)$ & \\
\hline $\mathrm{NN}$ & Int. ind. VC & Public VC & & 0.115 & & 0.230 & & $19.5(45.1)$ & 4.00 \\
\hline GK & $(30)$ & $(20)$ & & 0.083 & & 0.333 & & $22.3(47.9)$ & \\
\hline
\end{tabular}




\begin{tabular}{|c|c|c|c|c|c|c|c|c|c|}
\hline & $\begin{array}{c}\text { Treatment } \\
\text { (No. of obs.) }\end{array}$ & $\begin{array}{l}\text { Comparison } \\
\text { (No. of obs.) }\end{array}$ & $\begin{array}{c}\text { Probit-ps- } R^{2} \\
\text { before }\end{array}$ & $\begin{array}{c}\text { Probit-ps- } R^{2} \\
\text { after }\end{array}$ & $\begin{array}{c}\operatorname{Pr}>\chi^{2} \\
\text { before }\end{array}$ & $\begin{array}{c}\operatorname{Pr}>\chi^{2} \\
\text { after }\end{array}$ & $\begin{array}{c}\text { Med. (max.) } \\
\text { bias } \\
\text { before }\end{array}$ & $\begin{array}{c}\text { Med. (max.) } \\
\text { bias } \\
\text { after }\end{array}$ & $\begin{array}{c}\% \text { loss due } \\
\text { due to } \\
\text { CS }\end{array}$ \\
\hline \multicolumn{10}{|c|}{ Operational Veto rights (cont.) } \\
\hline NN & Local ind. VC & Bank-dep. VC & 0.083 & 0.027 & 0.021 & 0.629 & $9.6(66.5)$ & $7.8(15.5)$ & 8.62 \\
\hline GK & (66) & $(50)$ & & 0.009 & & 0.921 & & $4.3(12.5)$ & \\
\hline NN & Bank-dep. VC & Local ind. VC & & 0.013 & & 0.911 & & $10.4(19.3)$ & 0.00 \\
\hline GK & $(50)$ & $(66)$ & & 0.007 & & 0.956 & & $9.4(14.8)$ & \\
\hline $\mathrm{NN}$ & Int. ind. VC & Bank-dep. VC & 0.208 & 0.067 & 0.004 & 0.633 & $52.6(64.3)$ & $10.5(40.7)$ & 0.00 \\
\hline GK & (20) & $(50)$ & & 0.021 & & 0.849 & & $3.5(24.6)$ & \\
\hline $\mathrm{NN}$ & Bank-dep. VC & Int. ind. $\mathrm{VC}$ & & 0.156 & & 0.020 & & $34.1(56.4)$ & 12.86 \\
\hline GK & $(50)$ & $(20)$ & & 0.096 & & 0.099 & & $24.2(35.9)$ & \\
\hline $\mathrm{NN}$ & Int. ind. VC & Local ind. VC & 0.102 & 0.016 & 0.089 & 0.954 & $37.7(54.7)$ & $13.0(23.6)$ & 0.00 \\
\hline GK & $(20)$ & $(66)$ & & 0.016 & & 0.858 & & $7.9(16.0)$ & \\
\hline $\mathrm{NN}$ & Local ind. VC & Int. ind. VC & & 0.119 & & 0.020 & & $5.6(18.6)$ & 27.91 \\
\hline GK & $(66)$ & $(20)$ & & 0.107 & & 0.030 & & $6.5(12.4)$ & \\
\hline \multicolumn{10}{|c|}{ Structural Veto rights } \\
\hline NN & Bank-dep. VC & Public VC & 0.034 & 0.031 & 0.560 & 0.605 & $10.1(36.8)$ & $4.9(22.4)$ & 5.62 \\
\hline GK & $(58)$ & $(31)$ & & 0.030 & & 0.586 & & $14.1(15.9)$ & \\
\hline $\mathrm{NN}$ & Public VC & Bank-dep. VC & & 0.015 & & 0.937 & & $6.6(21.6)$ & 1.12 \\
\hline GK & $(31)$ & $(58)$ & & 0.003 & & 0.995 & & $5.7(11.1)$ & \\
\hline $\mathrm{NN}$ & Local ind. VC & Public VC & 0.091 & 0.055 & 0.027 & 0.108 & $30.0(46.9)$ & $12.2(31.4)$ & 4.88 \\
\hline GK & $(92)$ & $(31)$ & & 0.019 & & 0.651 & & $9.1(11.6)$ & \\
\hline $\mathrm{NN}$ & Public VC & Local ind. VC & & 0.022 & & 0.788 & & $7.6(22.7)$ & 0.00 \\
\hline GK & (31) & $(92)$ & & 0.004 & & 0.983 & & $3.3(10.1)$ & \\
\hline $\mathrm{NN}$ & Int. ind. VC & Public VC & 0.118 & 0.058 & 0.071 & 0.523 & $20.2(68.0)$ & $8.5(31.4)$ & 0.00 \\
\hline GK & $(31)$ & $(31)$ & & 0.013 & & 0.951 & & $8.5(17.1)$ & \\
\hline $\mathrm{NN}$ & Public VC & Int. ind. VC & & 0.029 & & 0.848 & & $4.9(35.8)$ & 4.84 \\
\hline GK & (31) & $(31)$ & & 0.031 & & 0.750 & & $12.4(22.2)$ & \\
\hline $\mathrm{NN}$ & Local ind. VC & Bank-dep. VC & 0.064 & 0.006 & 0.025 & 0.947 & $17.0(54.1)$ & $3.0(9.7)$ & 6.67 \\
\hline GK & $(92)$ & $(58)$ & & 0.006 & & 0.950 & & $1.5(8.5)$ & \\
\hline $\mathrm{NN}$ & Bank-dep. VC & Local ind. VC & & 0.009 & & 0.926 & & $7.3(17.2)$ & 0.00 \\
\hline GK & $(58)$ & $(92)$ & & 0.001 & & 0.999 & & $2.3(5.7)$ & \\
\hline NN & Int. ind. VC & Bank-dep. VC & 0.148 & 0.012 & 0.005 & 0.964 & $47.0(58.0)$ & $13.4(16.7)$ & 1.12 \\
\hline GK & $(31)$ & $(58)$ & & 0.004 & & 0.994 & & $2.5(12.8)$ & \\
\hline $\mathrm{NN}$ & Bank-dep. VC & Int. ind. VC & & 0.107 & & 0.039 & & $27.3(40.5)$ & 13.48 \\
\hline GK & $(58)$ & (31) & & 0.044 & & 0.372 & & $8.5(16.1)$ & \\
\hline $\mathrm{NN}$ & Int. ind. VC & Local ind. VC & 0.064 & 0.011 & 0.116 & 0.948 & $22.6(49.4)$ & $6.5(15.3)$ & 0.00 \\
\hline GK & $(31)$ & $(92)$ & & 0.004 & & 0.987 & & $2.7(12.2)$ & \\
\hline NN & Local ind. VC & Int. ind. VC & & 0.063 & & 0.064 & & $5.5(24.3)$ & 15.45 \\
\hline GK & $(92)$ & $(31)$ & & 0.053 & & 0.109 & & $2.9(8.8)$ & \\
\hline \multicolumn{10}{|c|}{ Liquidation rights } \\
\hline $\mathrm{NN}$ & Bank-dep. VC & Public VC & 0.044 & 0.015 & 0.333 & 0.835 & $9.6(42.6)$ & $3.1(15.3)$ & 5.77 \\
\hline GK & $(71)$ & (33) & & 0.020 & & 0.717 & & $9.2(14.7)$ & \\
\hline NN & Public VC & Bank-dep. VC & & 0.014 & & 0.942 & & $6.3(20.2)$ & 9.62 \\
\hline GK & $(33)$ & $(71)$ & & 0.003 & & 0.993 & & $2.2(10.0)$ & \\
\hline $\mathrm{NN}$ & Local ind. VC & Public VC & 0.100 & 0.042 & 0.010 & 0.182 & $22.7(56.7)$ & $10.1(24.0)$ & 5.22 \\
\hline GK & $(101)$ & (33) & & 0.013 & & 0.794 & & $4.0(9.8)$ & \\
\hline $\mathrm{NN}$ & Public VC & Local ind. VC & & 0.020 & & 0.805 & & $6.4(21.9)$ & 0.00 \\
\hline GK & $(33)$ & $(101)$ & & 0.001 & & 0.999 & & $2.9(3.6)$ & \\
\hline $\mathrm{NN}$ & Int. ind. VC & Public VC & 0.147 & 0.032 & 0.021 & 0.808 & $35.0(64.5)$ & $8.2(31.4)$ & 0.00 \\
\hline GK & $(32)$ & (33) & & 0.015 & & 0.926 & & $7.5(27.2)$ & \\
\hline $\mathrm{NN}$ & Public VC & Int. ind. VC & & 0.026 & & 0.861 & & $6.0(33.5)$ & 4.62 \\
\hline GK & (33) & $(32)$ & & 0.022 & & 0.853 & & $5.9(16.7)$ & \\
\hline NN & Local ind. VC & Bank-dep. VC & 0.104 & 0.008 & 0.000 & 0.900 & $29.9(67.5)$ & $2.3(8.9)$ & 5.81 \\
\hline GK & $(101)$ & $(71)$ & & 0.010 & & 0.806 & & $3.1(10.7)$ & \\
\hline $\mathrm{NN}$ & Bank-dep. VC & Local ind. VC & & 0.006 & & 0.955 & & $6.0(14.1)$ & 0.00 \\
\hline GK & $(71)$ & $(101)$ & & 0.002 & & 0.996 & & $2.7(7.5)$ & \\
\hline $\mathrm{NN}$ & Int. ind. VC & Bank-dep. VC & 0.207 & 0.012 & 0.000 & 0.960 & $63.3(70.0)$ & $6.7(26.4)$ & 0.97 \\
\hline GK & (32) & $(71)$ & & 0.005 & & 0.984 & & $5.2(18.5)$ & \\
\hline $\mathrm{NN}$ & Bank-dep. VC & Int. ind. VC & & 0.136 & & 0.004 & & $31.2(44.9)$ & 18.81 \\
\hline GK & $(71)$ & $(32)$ & & 0.060 & & 0.133 & & $10.8(16.7)$ & \\
\hline $\mathrm{NN}$ & Int. ind. VC & Local ind. VC & 0.075 & 0.000 & 0.052 & 1.000 & $28.1(54.8)$ & $0.0(0.6)$ & 0.00 \\
\hline GK & $(32)$ & $(101)$ & & 0.005 & & 0.966 & & $6.2(12.3)$ & \\
\hline $\mathrm{NN}$ & Local ind. VC & Int. ind. VC & & 0.055 & & 0.080 & & $6.0(19.8)$ & 15.04 \\
\hline GK & $(101)$ & $(32)$ & & 0.051 & & 0.094 & & $7.0(12.8)$ & \\
\hline
\end{tabular}

Notes: Explanation of indicators see table 10. 


\section{CFS Working Paper Series:}

\begin{tabular}{|c|c|c|}
\hline No. & Author(s) & Title \\
\hline $2006 / 12$ & $\begin{array}{l}\text { Julia Hirsch } \\
\text { Uwe Walz }\end{array}$ & $\begin{array}{l}\text { Why Do Contracts Differ between VC Types? } \\
\text { Market Segmentation versus Corporate } \\
\text { Governance Varieties }\end{array}$ \\
\hline $2006 / 11$ & $\begin{array}{l}\text { Carsten Bienz } \\
\text { Julia Hirsch }\end{array}$ & The Dynamics of Venture Capital Contracts \\
\hline $2006 / 10$ & $\begin{array}{l}\text { Renata Bottazzi } \\
\text { Tullio Jappelli } \\
\text { Mario Padula }\end{array}$ & $\begin{array}{l}\text { Retirement Expectations, Pension Reforms, and } \\
\text { Their Impact on Private Wealth Accumulation }\end{array}$ \\
\hline 2006/09 & $\begin{array}{l}\text { Markus Haas } \\
\text { Stefan Mittnik } \\
\text { Marc S. Paolella }\end{array}$ & Multivariate Normal Mixture GARCH \\
\hline $2006 / 08$ & $\begin{array}{l}\text { Elena Carletti } \\
\text { Philipp Hartmann } \\
\text { Giancarlo Spagnolo }\end{array}$ & Bank Mergers, Competition and Liquidity \\
\hline $2006 / 07$ & $\begin{array}{l}\text { Alexander Muermann } \\
\text { Stephen H. Shore }\end{array}$ & $\begin{array}{l}\text { Strategic Trading and Manipulation with Spot } \\
\text { Market Power }\end{array}$ \\
\hline 2006/06 & $\begin{array}{l}\text { Jan Pieter Krahnen } \\
\text { Frank A. Schmid } \\
\text { Erik Theissen }\end{array}$ & $\begin{array}{l}\text { Investment Performance and Market Share: A } \\
\text { Study of the German Mutual Fund Industry }\end{array}$ \\
\hline $2006 / 05$ & Jan Pieter Krahnen & $\begin{array}{l}\text { Die Stabilität von Finanzmärkten: Wie kann die } \\
\text { Wirtschaftspolitik Vertrauen schaffen? }\end{array}$ \\
\hline $2006 / 04$ & $\begin{array}{l}\text { Jan Pieter Krahnen } \\
\text { Christian Wilde }\end{array}$ & $\begin{array}{l}\text { Risk Transfer with CDOs and Systemic Risk in } \\
\text { Banking }\end{array}$ \\
\hline $2006 / 03$ & $\begin{array}{l}\text { Panos Parpas } \\
\text { Berc Rustem } \\
\text { Volker Wieland } \\
\text { Stan Zakovic }\end{array}$ & $\begin{array}{l}\text { Mean Variance Optimization of Non-Linear } \\
\text { Systems and Worst-case Analysis }\end{array}$ \\
\hline
\end{tabular}

Copies of working papers can be downloaded at http://www.ifk-cfs.de 